\title{
SPHERICAL TORUS, COMPACT FUSION AT LOW FIELD
}

\author{
Y-K. M. Peng
}

Fusion Engineering Design Center

Date Published - February 1985

\section{DISCLAMMER}

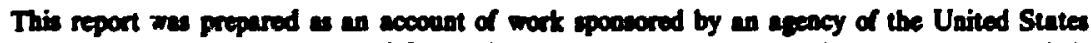
Covernment. Nether the United Staten Governmeat sor any apency thereol, sor any of their

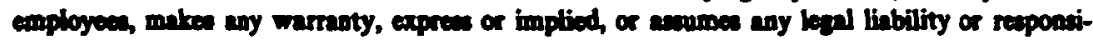
bility for the scenrecy, completesenes of usefulnoses of any information, appantus, product, or

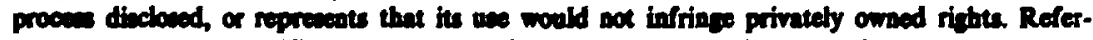

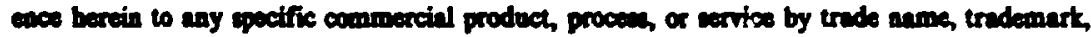

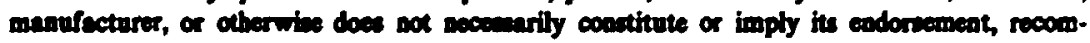

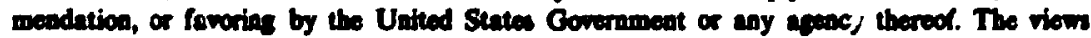

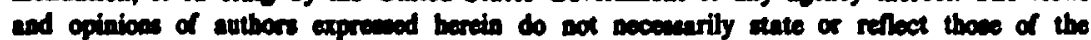
United States Covenamat of say apercy theor of.

\section{Prepare $\mathrm{I}$ by the}

OAK RIDGE NATIONAL LABORATORY

Oak Ridge, Tennescee $\mathbf{3 7 8 3 1}$ operated by

MARTIN MARIETTA ENERGY SYSTEMS, INC.

for the

U.S. DEPARTMENT OF ENERGY under Contract No. DE-ACOS-840R21400 


\section{CONTENTS}

ABSTRACT $\ldots \ldots \ldots \ldots \ldots \ldots \ldots \ldots \ldots \ldots \ldots \ldots \ldots \ldots \ldots \ldots \ldots \ldots \ldots$

1. MOTIVATION $\ldots \ldots \ldots \ldots \ldots \ldots \ldots \ldots \ldots \ldots \ldots \ldots \ldots \ldots \ldots \ldots \ldots \ldots \ldots$

2. PHYSICS ASSUMPTIONS $\ldots \ldots \ldots \ldots \ldots \ldots \ldots \ldots \ldots \ldots \ldots \ldots \ldots$

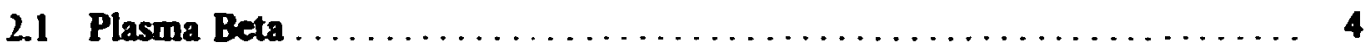

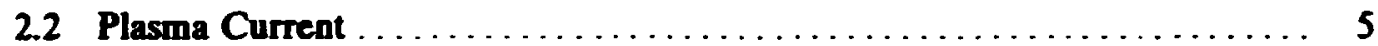

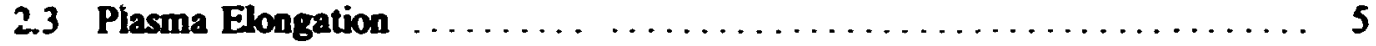

2.4 Plasma Energy Confinement $\ldots \ldots \ldots \ldots \ldots \ldots \ldots \ldots \ldots \ldots \ldots \ldots$

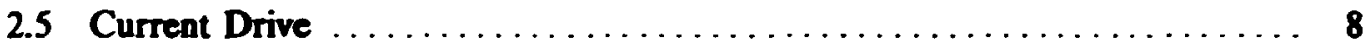

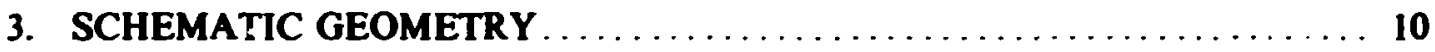

4. PARAMETER SPACE AND EXAMPLES OF D-T SPHERICAL TORI $\ldots \ldots \quad 12$

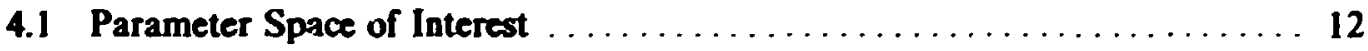

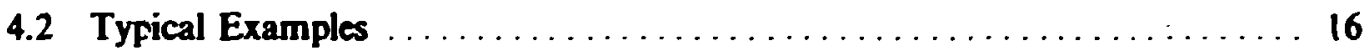

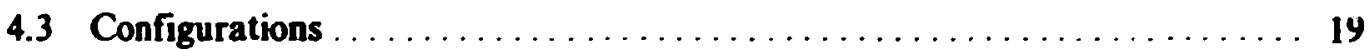

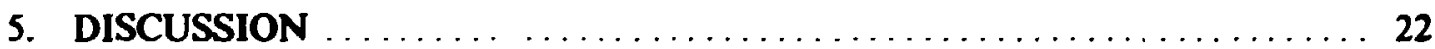

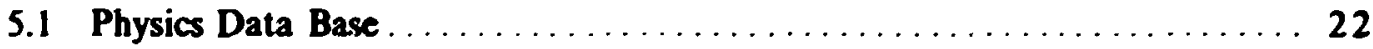

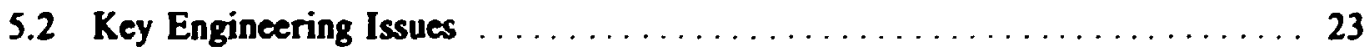

5.3 Comparison With High-Performance TFCX $\ldots \ldots \ldots \ldots \ldots \ldots \ldots \ldots$

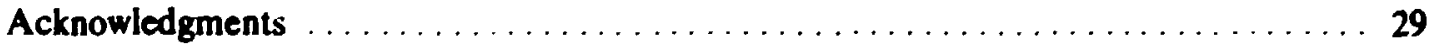

References $\ldots \ldots \ldots \ldots \ldots \ldots \ldots \ldots \ldots \ldots \ldots \ldots \ldots \ldots \ldots \ldots \ldots \ldots \ldots \ldots, 29$ 


\section{ABSTRACT}

A spherical torus is obtained by retaining only the indispensable components on the inboard side of a tokamak plasma, such as a cooled, normal conductor that carries current to produce a toroidal magnetic field. The resulting device features an exceptionally small aspect ratio (ranging from below 2 to about 1.3), a naturally elongated D-shaped plasma cross section, and ramp-up of the plasma current primarily by noninductive means. As a result of the favorable dependence of the tokamak plasma behavior to decreasing aspect ratio, a spherical torus is projected to have small size, high beta, and modest field. Assuming Mirnow confinement scaling, an ignition spherical torus at a field of $2 \mathrm{~T}$ features a major radius of $1.5 \mathrm{~m}$, a minor radius of $1.0 \mathrm{~m}$, a plasma current $\mathrm{c}^{\varepsilon}: 4 \mathrm{MA}$, comparable toroidal and poloidal field coil currents, an average beta of $24 \%$, and a fusion power of $50 \mathrm{MW}$. At $2 \mathrm{~T}$, a $Q=1$ spherical torus will have a major radius of $0.8 \mathrm{~m}$, a minor radius of $0.5 \mathrm{~m}$, and a fusion power of a few megawatts. 


\section{MOTTVATION}

So far, tokamak physics developments bave outstripped other magnetic fusion approaches. The engineering embodiment of the tokamak has made significant progress but continues to be perceived as less than attractive to potential users. Serious design concept ievelopment for a device to carry out ignition and burn physics and fusion engineering deveiopment in magnetic fusion has been in progress for several years. Prominent concepts include the Engineering Tes, Facility (ETF), ${ }^{1}$ the International Tokamak Reactor (INTOR), ${ }^{2}$ the Fusion Engineering Device (FED), ${ }^{3}$ and the Toroidal Fusion Core Experimert (TFCX). The estimated, direct total cost is about $\mathbf{S I}$ billion or more with perceived high risk in achieving the stated performance goals. It appears that continued progress of fusion can be enhanced if concepts can be found with more favorable cost risk-to-benefit ratios' (i.e., embodiments with small unit size and limited risk in reaching adequate plasma and fusion engineering performances). The spherical torus concept is iniroduced here with this in mind.

Major factors that contribute to the larger size and higier cort of the aforementioned design studies can be traced to a combination of physics assumptions, engineering criteria, and conventional tokamak wisdom. The conventional wisdom of tokamak operation and prudent engineering suggests the inclusion of a solenoid for inductive current drive, nuclear shields inboard to the plasma for protection of inboard coils and insulators, and a separate first wall and vacuum boundary. These tend to increase the major radius and aspect ratio (major radius divided by minor radius), which, in turn, leads to modest values of average beta (the plasma pressure divided by magnetic field pressure, typically around $5 \%$ for aspect ratios of around 3). In the physics area, the assumed plasma energy confinement efficiency at reactor conditions leads to large plasma major and minor radii (around $3 \mathrm{~m}$ 
or more and $1 \mathrm{~m}$ or so, respectively) and plasma curreat (6 to $12 \mathrm{MA}$ ) when intermediate values of magnetic field (4 to $6 \mathrm{~T}$ ) are employed. For ignition devices with significant burn, a typical design has about $100 \mathrm{~m}^{3}$ in plasma volume, has $100 \mathrm{MJ}$ in plasma thermal energy content, and produces about $200-\mathrm{MW}$ deuterium-tritium (D-T) fusion power. The laiest cost estimate for such a device using copper toroidal field (TF) coils ${ }^{4}$ is around SI billion.

In the spherical torus concept, only what is absolutely indispensable inboard to the plasma is retained. This includes the normal, cooled conductor that carries current to produce the toroidal magnetic field required by tokamak plasmas. Other components, such as the solenoid, shield, and organic insulator, are eliminated. Inorganic insulators or separate first wall and vacuum boundary arrangements can a'so be eliminated by feasible approaches if favorable design trade-offs are indicated. The resulting plasma has an exceptionally small aspect ratio (less than 2 and typically around 1.5 ), appearing much like a sphere with a modest hole through the center, suggesting the name of spherical torus (Fig. 1). This simplification in configuration, plus the plasma improvements due to decreasing aspect ratio suggested by our present understanding of tokamuk physics, engenders the high potential of the spherical torus. Assuming that the scaling of plasma behavior toward very small aspect ratios is as expected, a typical ignition and burn spherical torus with a magnetic field of $\angle 1$ at the plasma center will have a major radius of $1.5 \mathrm{~m}$, a minor radius of $1.0 \mathrm{~m}$, a plasma current of $14 \mathrm{MA}$, comparable currents in the TF and poloidal field (PF) coils, an average beta of $24 \%$, a fusion power of $50 \mathrm{MW}$, and a plasma thermal energy content of $30 \mathrm{MJ}$. A spherical torus driven near $: ?=1$ at a fusion power of a few megawatts and using a 2-T field will have a plasma energy content of a few megajoules and major and minor radii about $0.8 \mathrm{~m}$ and $0.5 \mathrm{~m}$, respectively. 


\section{ORNL-DWG 84-3421 FED}
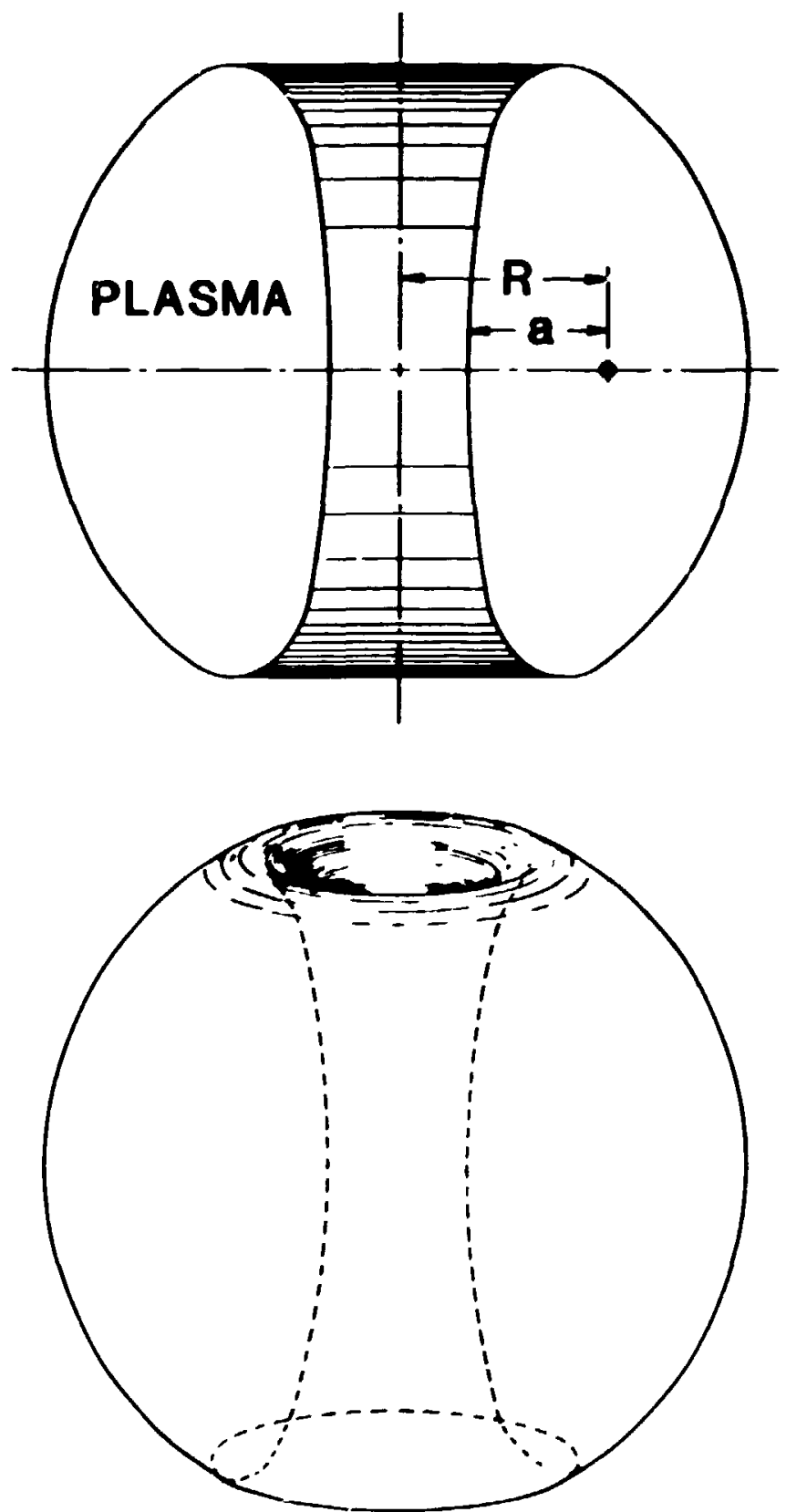

Figure 1 The plasma configuration of a sphericai torus, a tokamak plasma with very small aspect ratio and large elongation. 
The major parameters for a spherical torus are dictated primarily by a combination of physics assumptions and engineering and geometric requirements. Simplified formulas are used here to reveal the domain of interest in parameter space. More detailed assessments will be necessary for the key engineering issues to ensure realistic approaches for the various embodiments of the spherical torus concept.

\section{PHYSICS ASSUMPTIONS}

Plasma properties that determine the major parameters of a tokamak and its performance include plasma energy confinement time, plasma beta, and current drive. These, in turn, are strongly dependent on the shape of the plasma cross section and the magnitude of plasma current. The effects of a very small aspect ratio on these plasma properties for a spherical torus are highlighted in the following.

\subsection{Plasma Beta}

Recent calculations ${ }^{6}$ of experimental results of tokamak beta have suggested a scaling of the form

$$
\beta_{c}=0.27 \kappa^{1.2}(1.0+1.5 \delta) / A^{1.3} q^{1.1}
$$

where $\alpha$ is the plasma elongation (heighl-io-width ratio of the plasma cross section), $\delta$ is the triangularity (the inward shift of the apex divided by the plasma minor radius $a$ ), $A$ is the aspect ratio, and $q$ is the plasnia safety factor at the bounciary. More recent comparieons? with magnetohydrodynamic (MHL) stability analysis have coalesced the influences of these plasma parameters into the plasma current, giving 


$$
\beta_{c}=C_{\beta} I_{P}(\mathrm{MA}) / a(\mathrm{~m}) B(\mathrm{~T}) \text {, }
$$

where the latest assessment' of the value $C_{\beta}$ is about $0.033, I_{P}$ is the plasma current, and $B$ is the toroidal magnetic field at the plasma center. It is seen that beta either increases with increasing $\alpha$ and with decreasing $A q$ or increases with increasing $I f a B$. It is convenjent here to use Eq. (2), although no da.a are currently available at $A$ near 1.5 to validate either scaling relation for our application.

\subsection{Plasma Current}

MHD equilibrium calculations are carried out to quantify th.: $I_{P}$ dependence on $A$ for small $A$. We find

$$
I_{P}(\mathrm{MA})=[5 a(\mathrm{~m}) B(\mathrm{~T}) / q]\left[C_{I} \epsilon /\left(1-\epsilon^{2}\right)^{2}\right]\left[\left(1+\kappa^{2}\right) / 2\right],
$$

where $\epsilon$ is $1 / A$ and $C_{I}=1.22-0.68 \epsilon$. The strong toroidicity introduced as $A$ approaches 1 permits large increases of $I_{P}$ without reducing $q$ to unacceptably low values. Figure 2 shows an example of an equilibrium with $A=1.5, B=2 \mathrm{~T}$, plasma major radius $R=$ $1.34 \mathrm{~m}, a=0.88 \mathrm{~m}$, safety factor $q=2.4, \beta=0.26$, and $I_{P}=14$ MA. Note that the average beta value here is not inconsistent with earlier MHD stability calculations.

\subsection{Plasma Elongation}

For tokamaks with $A$ around 3 , it is generally found that large shaping fields (quadrupole and hexapole fields) are needed to achieve an elongation of 1.6 with mild triangularity.? 
6

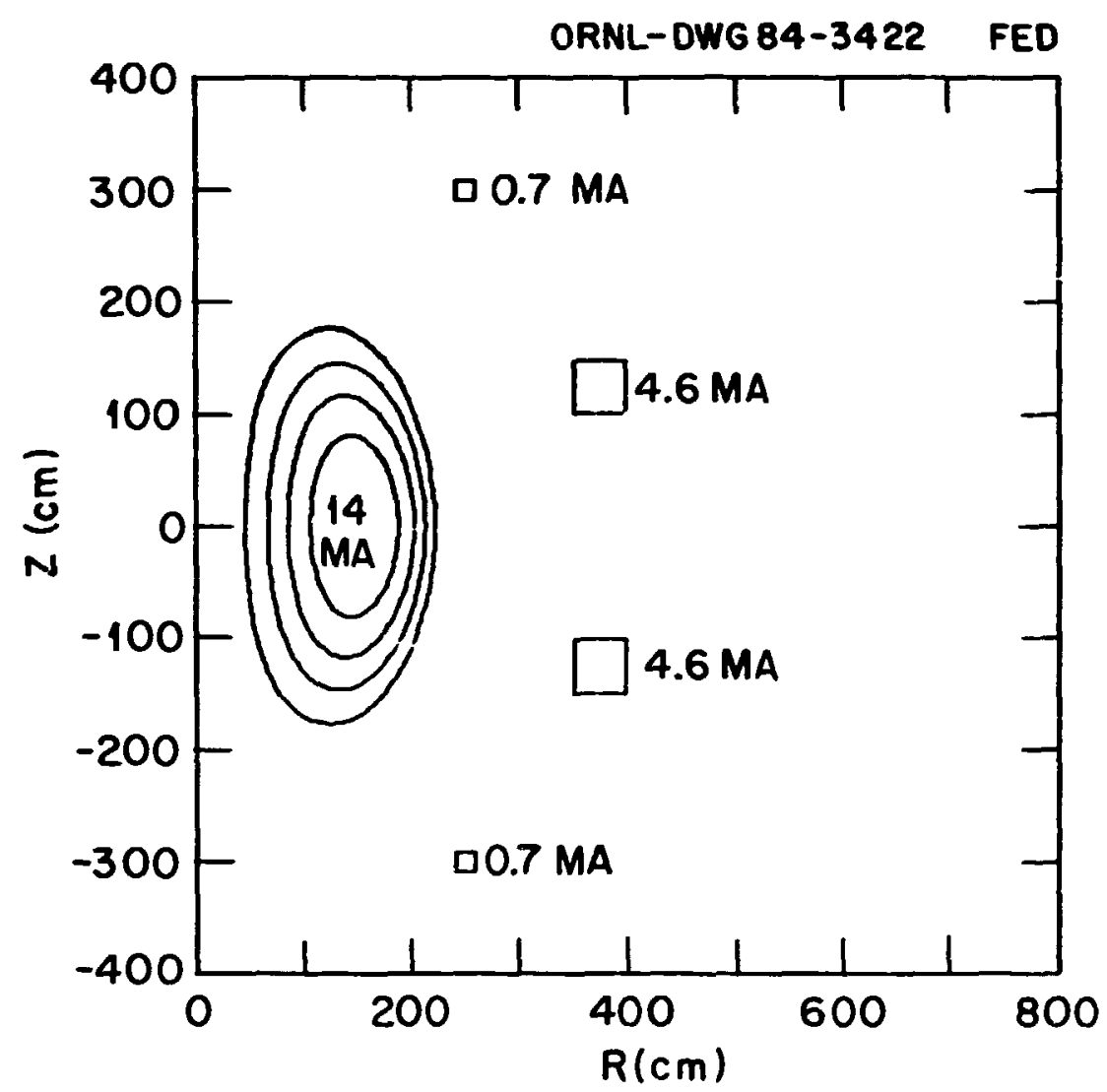

Figure 2 Plasma nux surfaces and PF coil arrangement for a spherical torus at $B=2 \mathrm{~T}, R=1.34 \mathrm{~m}, a=$ c.88 $\mathrm{m}, \alpha=2, \Delta=0.1 a, I_{p}=14 \mathrm{MA}$, and $\beta=27 \%$. The currents in the PF coils in megamperes are also indicated.

When the PF coils are external to the TF coil bore, the total coil current amounts to several times the plasma current. As $A$ is reduced to around 1.5 , it is observed that the plasma elongates naturally without a significant shaping field. As indicated in Fig. 3, only an external dipole vertical field is required to achieve an elongation of 2 . Th. + translates to simple PF coils with relatively low currents. As shown in Fig. 2, the tutal ampere-turns in the PF coils amount to $10.6 \mathrm{MA}$. 

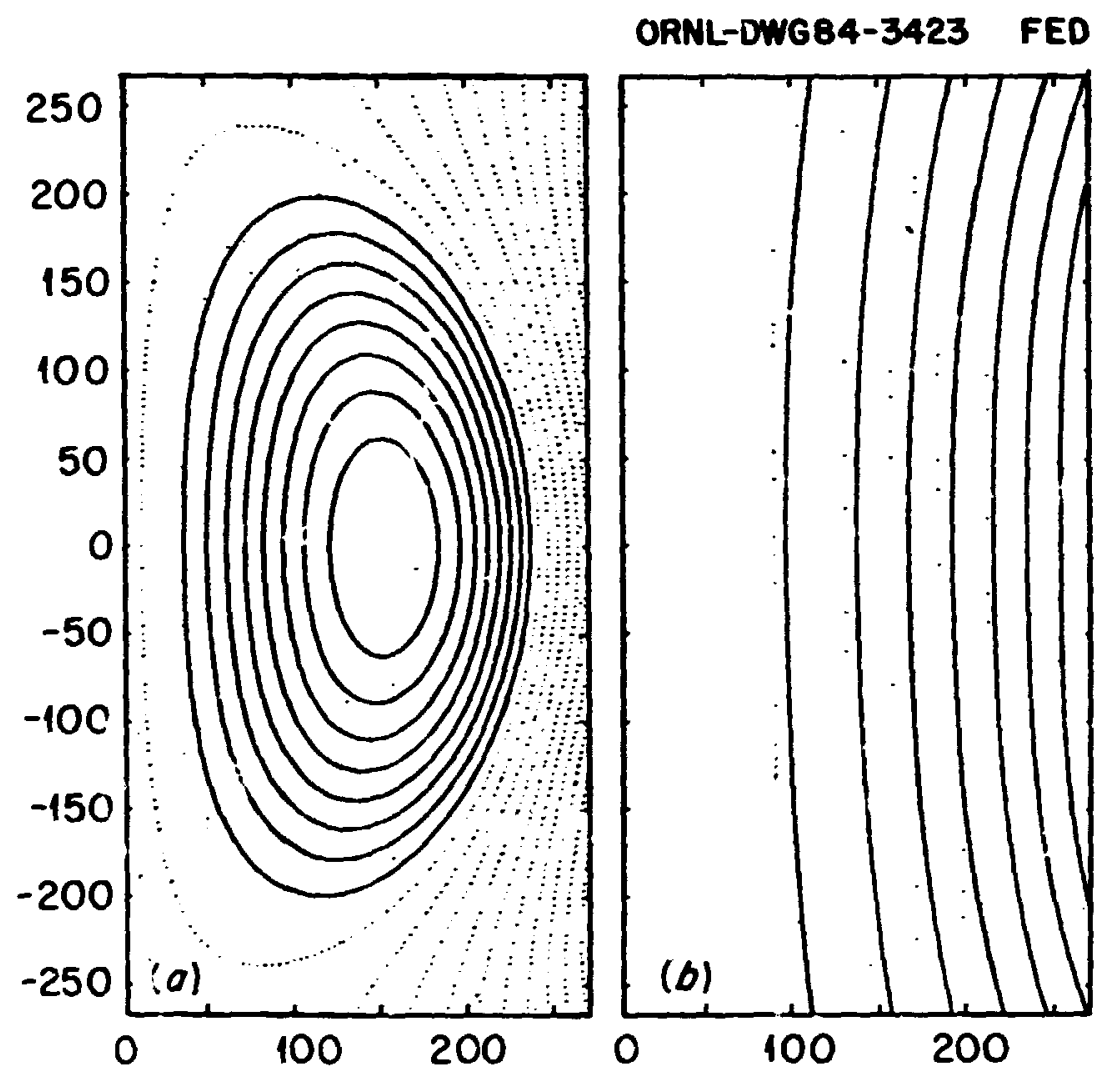

Figure 3 (a) Poloidal hux surfaces of a spherical torus and (b) the external vertical magnetic field.

\subsection{Plasma Energy Confinement}

A consequence of compactness is a reduced confinement time if confinement indeed scales with the size of the plasma. Recent experimental indications, however, point to a strong scaling of plasma confinement with plasma current in plasmas with intense auxiliary heating. The Mirnov scaling ${ }^{10}$ employed as the reference scaling in the TFCX design studies ${ }^{4}$ serves as an example in this case:

$$
\tau(\mathrm{s})=0.39 a(\mathrm{~m}) I_{P}(\mathrm{MA})
$$


The latest good confinement results in the so-called $\mathrm{H}$-mode ${ }^{11}$ and continuous H-mode ${ }^{12}$ also indicate positive scaling with $I_{\boldsymbol{F}}$. Although it is presently far from certain whether this scaling will indeed adequately describe energy confinement in TFCX or in an ignition spherical torus, it is used here to facilitate an objective comparison between the two. The impact of other major confinement scaling assumptions on the merits of the spherizal torus will be a subject of near-term interest.

\subsection{Current Drive}

Small major radii and aspect ratios lead to small plasma inductance and facilitate current drive by reducing the flux required through external sources. This can be seen in the following approximation to the plasma self-inductance:

$$
L_{P}(H)=\mu_{0} R\left[\ln (8 A / \sqrt{\kappa})-2+\left(\ell_{i} / 2\right)\right] \text {, }
$$

where $R$ is the major radius and $\ell_{i}$ is the internal inductivity of the plasma, which in the case of a spherical torus with $q=2.4$ is around 0.7 . The plasma self-inductance of an ignition spherical torus with $R=1.5 \mathrm{~m}$ is then estimated to be less than $1 \mu \mathrm{H}$, roughly a quarter of that in the smallest conventional TFCX option.

Whereas a small $R$ will permit at most a modest solenoid inboard to the plasma, it is expected to help permit current ramp-up by noninductive means, such as the lower hybrid resonance frequency waves at modest plasma densities and temperatures. ${ }^{13}$ The steadystate current maintenance power requirement, as suggested by several experiments at modest plasma densities and temperatures, can be given approximately as ${ }^{14}$

$$
P_{C D}(\mathrm{MW})=\left[n\left(10^{20} \mathrm{~m}^{-3}\right) R(\mathrm{~m}) I_{P}(\mathrm{MA}) / 0.074 T_{e}(\mathrm{keV})\right]
$$


In view of the relatively high current ramp-up efficiencies achieved in PLT $^{13}$ with densities up to $6 \times 10^{12} \mathrm{~cm}^{-3}$, this approximation is useful in extimating the current rarap-up power $P_{R U}$ near this density and at 1 to $2 \mathrm{keV}$.

The ability to maintain the plasma current by noninductive means at high densities during ignition and burn is not experimentally verified at the present time. If acoess of the If wave into the plasma core can be accomplished in a spherical torus, the requirement of current maintenance may be acceptable in view of the current profile shown in Fig. 4. It is seen that for a spherical torus of modest $q$ and poloidal beta values, the self-consistent toroidal current density profile can be bollow. This is qualitatively consistent with the current profiles maintained by externally launched rf waves.

In the event that current maintenance during burn at adequate densities remains unavailable, if current ramp-up can still be applied periodically to recover full plasma current at low derisities in nonignited plasmas. Each burn pulse will then be limited to the resistive plasma decay allowed by proper spherical torus operations. The plasma current will Hecay by $10 \%$ in about $100 \mathrm{~s}$ if classical resistance is assumer in an ignition spherical torus.
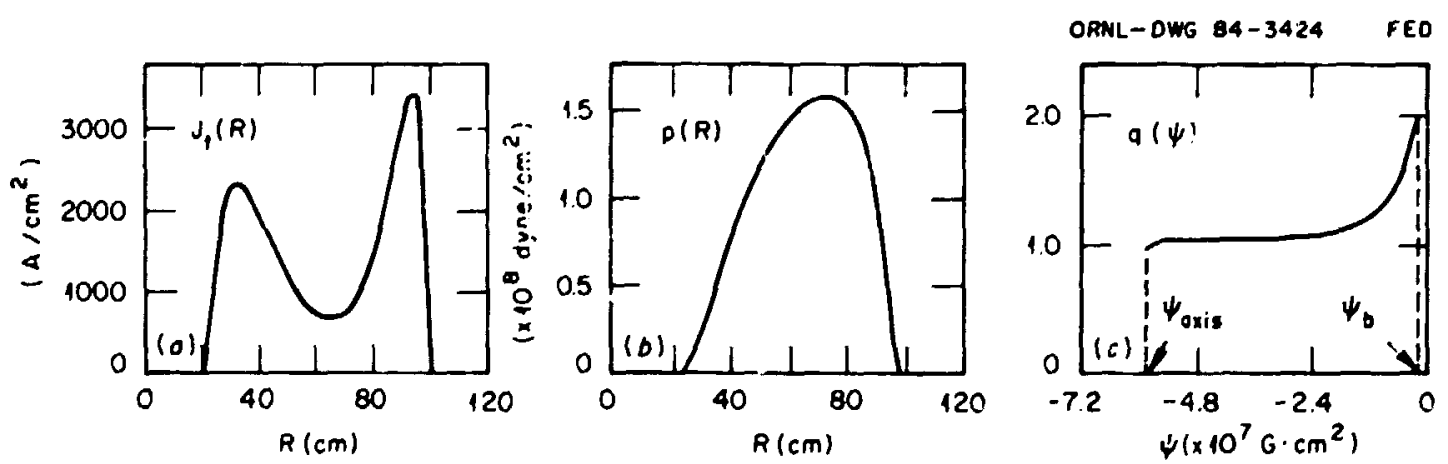

¿gure 4 (a) The toroidal plasma current profile, (b) the plasma preasure praile, and (c) the safety factor profile of an $A-1.5$ spherical torus with elongation of 1.6 and a poloidal beta of 0.75 . 


\section{SCHEMATIC GEOMETRY}

A schematic of a typical D-T spherical torus device is given in Fig. 5, which depicts key parameters. Variations to the various components in the figure will be investigated as part of a continued effort to clarify the potential of spherical tori. For example, the conductor arrangements that carry the return current from the center conductor post can be located at varying degrees of proximity to the plasma, including the possibility of being a part, or all, of the first wall arrangement. The distance between the plasma inboard edge end the surface of the center conductor post, $\Delta$, can be increased to accommodate a separate first wall and vacuum boundary anangement, at the expense of increasing the aspect ratio somewhat. The following relationships corresponding to the geometry of Fig. 5 are used in the scoping assessment that follows.

The radius of the center conductor post, $\boldsymbol{R}_{c}$ can be determined by

$$
R_{c}=r_{c}+\left[r_{c}^{2}+2(a+\Delta) r_{c}\right]^{1 / 2}, \quad r_{c}=B / \mu_{0} J_{c}
$$

where $J_{c}$ is thc current density over the entire cross section of the conductor post. The plasma volume $V_{P}$ is approximated by

$$
V_{P}=2 \pi^{2} R a^{2} x
$$

and the plasma thermal energy content $W_{P}$ is approximated by

$$
W_{P}(\mathrm{MJ})=0.05 n\left(10^{20} \mathrm{~m}^{-3}\right) T(\mathrm{keV}) V_{P}\left(\mathrm{~m}^{3}\right)
$$




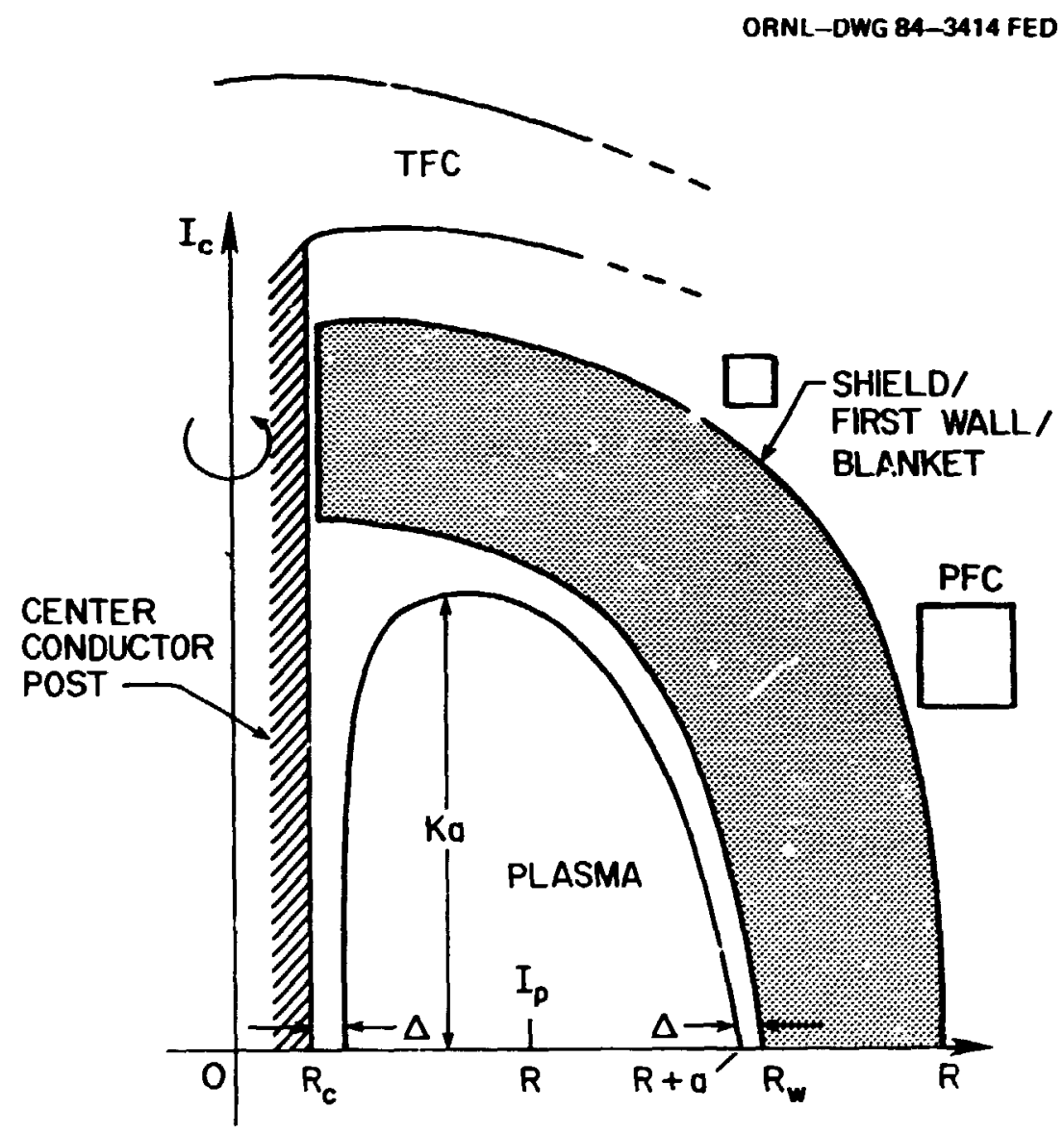

Figure 5 A schematic geometry of spherical torus, showing a typical example of the arrangement of the center conductor post, TF coil return legs (TFC), PF coils (PFC), the shield/first wall/blankei location, and the relative plasma location.

where $n$ and $T$ are the average plasma density and temperature, respectively. The D-T fusion power $\boldsymbol{P}_{D T}$ is estimated by

$$
P_{D T}(\mathrm{MW})=2.82\left[n\left(10^{20} \mathrm{~m}^{-3}\right) / 2\right]^{2}\langle\sigma v\rangle\left(10^{-22} \mathrm{~m}^{3} / \mathrm{s}\right) V_{P}\left(\mathrm{~m}^{3}\right)
$$

where $\langle\sigma \nu\rangle$ is the average D-T fusion cross section and is dependent primarily on $T$. The average neutron wall load $W_{L}$ is roughly given by 


$$
W_{L}\left(\mathrm{MW} / \mathrm{m}^{2}\right)=0.8 P_{D T} / 4 \pi R_{w}^{2}
$$

where $R_{w}=R+a+\Delta$, the radius of the first wall measured from the center of the spherical torus. Note that the average quantities used here tend to give pessimistic values of $\boldsymbol{P}_{D T}$. This tends to compensate for the optimism associater with the simpiified plasma formulas (e.g., the omission of plasma impurities). With these, the required auxiliary power $\boldsymbol{P}_{\text {eux }}$ is roughly given by

$$
P_{\text {oux }}=\left(W_{P} / \tau\right)-\left(P_{D T} / 5\right)
$$

Finally, for comparison with TFCX, the plasma ignition parameter $C_{\mathrm{R}}$ used in the TFCX studies,

$$
C_{i g}=0.295 \beta_{c} r(\mathrm{~s}) B^{2}(\mathrm{~T}) \text {, }
$$

is also used here.

\section{PARAMETER SPACE AND EXAMPLES OF D-T SPHERICAL TORI}

\subsection{Parameter Space of Int:rest}

The parameter space of interest is assessed using the foregoing formulas. For a range of $B$ from. 1 to $3 \mathrm{~T}$ and $C_{i g}$ from 0.5 to 1.5 and assuming $q=2.4, \Delta=0.1 a, \kappa=2$, and $J_{c}=$ $3 \mathrm{kA} / \mathrm{cm}^{2}$, the domain in $a, R$, and $I_{p}$ of interest for the spherical torus is shown in

Fig. 6. It is seen that relatively modest values of $R$ (from 0.9 to $1.7 \mathrm{~m}$ ) and $a$ (from 0.5 to 


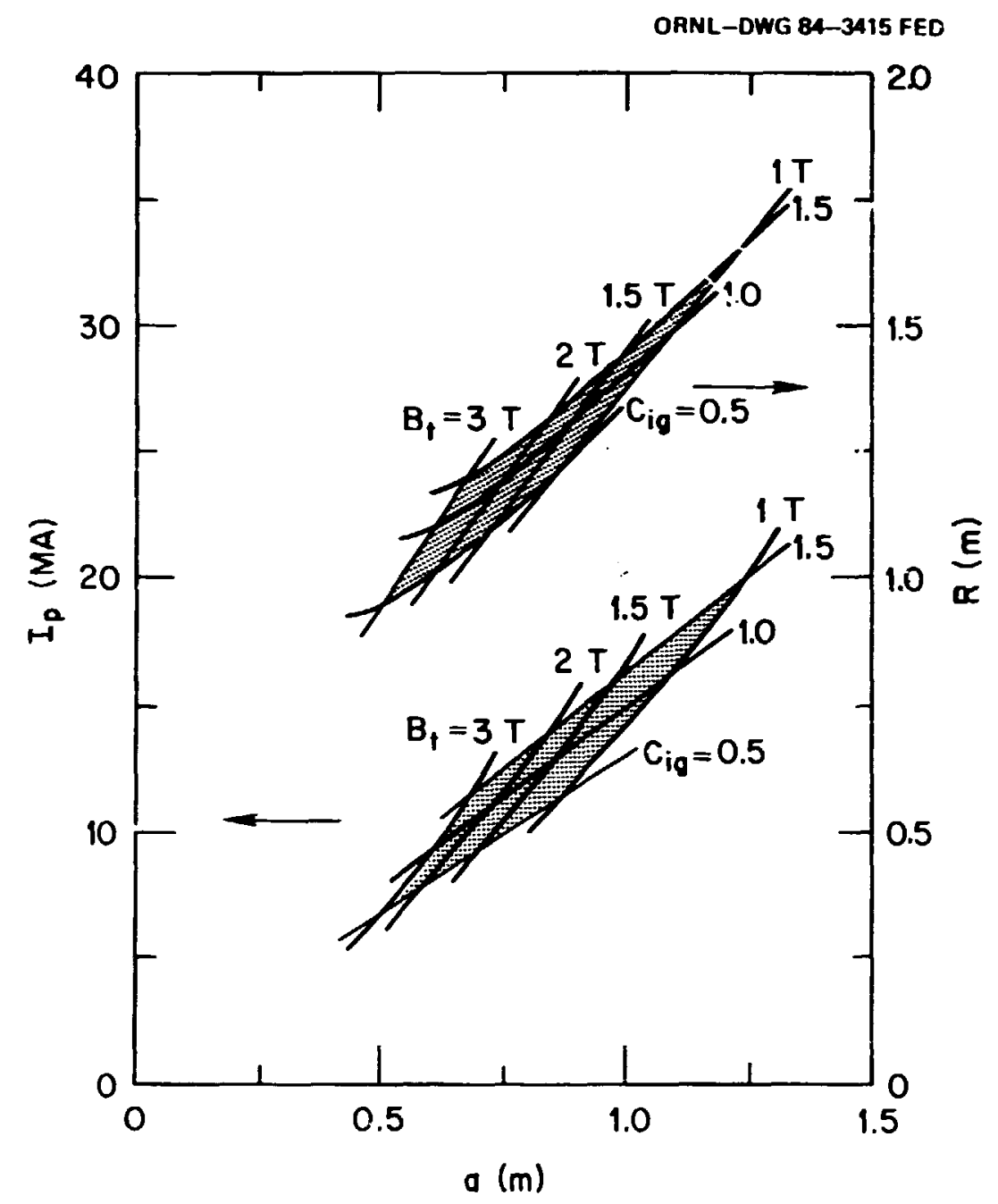

Figure 6 The parameter space of interest in $a, R$, and $I_{p}$ for spherical tori having $B$ between $I$ and $3 \mathrm{~T}, C_{4 q}$ between 0.5 and $1.5, q=2.4, \Delta=0.1 a . \kappa=2$, and $J_{c}=3 \mathrm{kA} / \mathrm{cm}^{2}$.

$1.2 \mathrm{~m}$ ) are obtained with plasma current having a range of 6 to 20 MA. For these spherical tori, the total current in the center conductor post has a range of 6 to $18 \mathrm{MA}$, similar to $I_{P}$ in magnitude (Fig. 7). As seen from Figs. 8 and 9 , the same range in $I_{P}$ and $I_{c}$ is indicated for average neutron wall load $W_{L}$ from 0.25 to $1.0 \mathrm{MW} / \mathrm{m}^{2}$ and for D-T power $P_{D T}$ from several to $100 \mathrm{MW}$. 


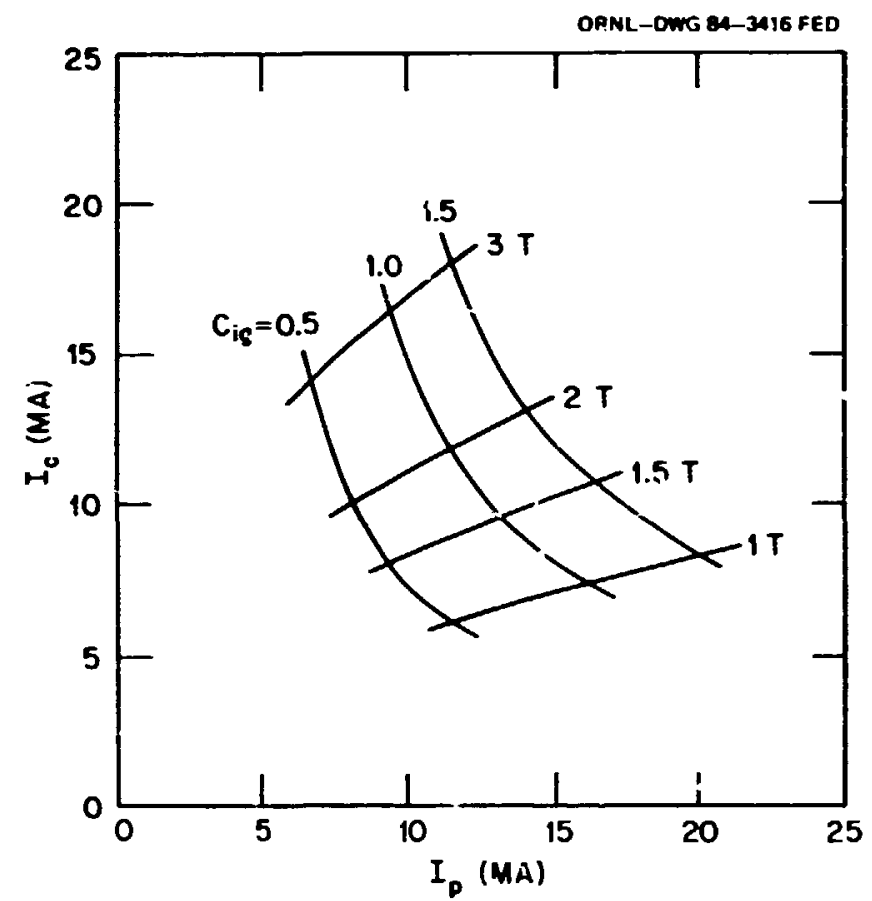

Figure 7 The parameter space _. interest in $I_{\rho}$ and $I_{c}$ for spherical tori having $B$ between 1 and $3 T, C_{l_{q}}$ between 0.5 and 1.5 , and those parameters of Figure 6.

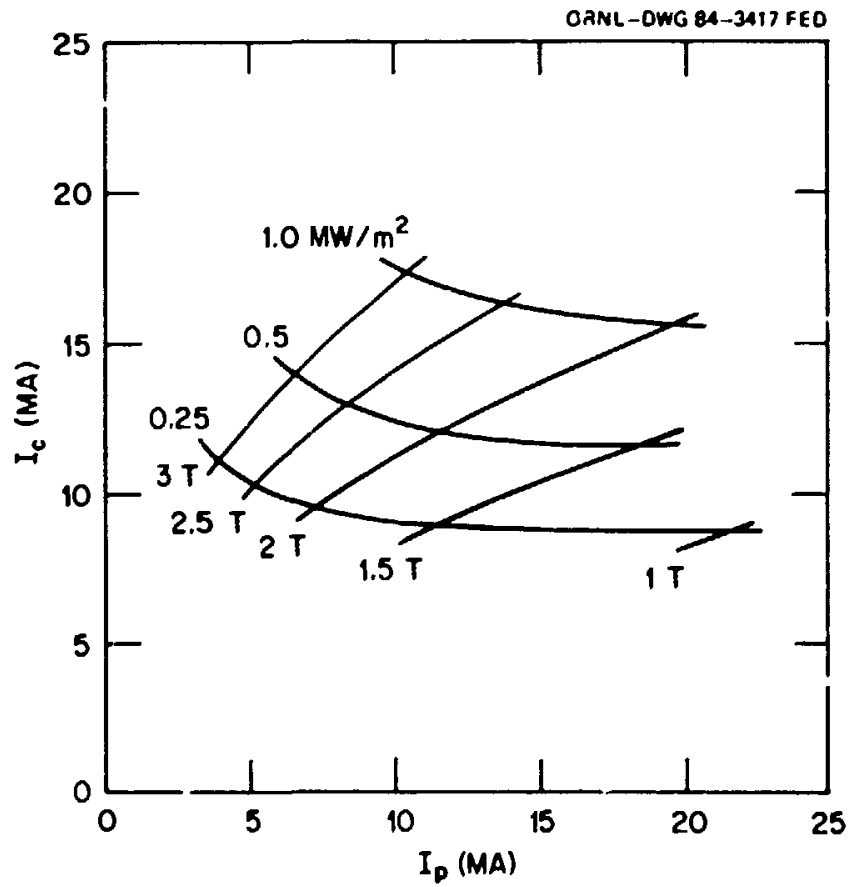

Pigure 8 The parameter space of intereat in $I_{F}$ and $I_{e}$ for spherical tori having $B$ between $I$ and $3 T, W_{L}$ between $0.25 \mathrm{MW} / \mathrm{m}^{2}$ and $1.0 \mathrm{MW} / \mathrm{m}^{2}$, and those parameters of Figure 6 . 


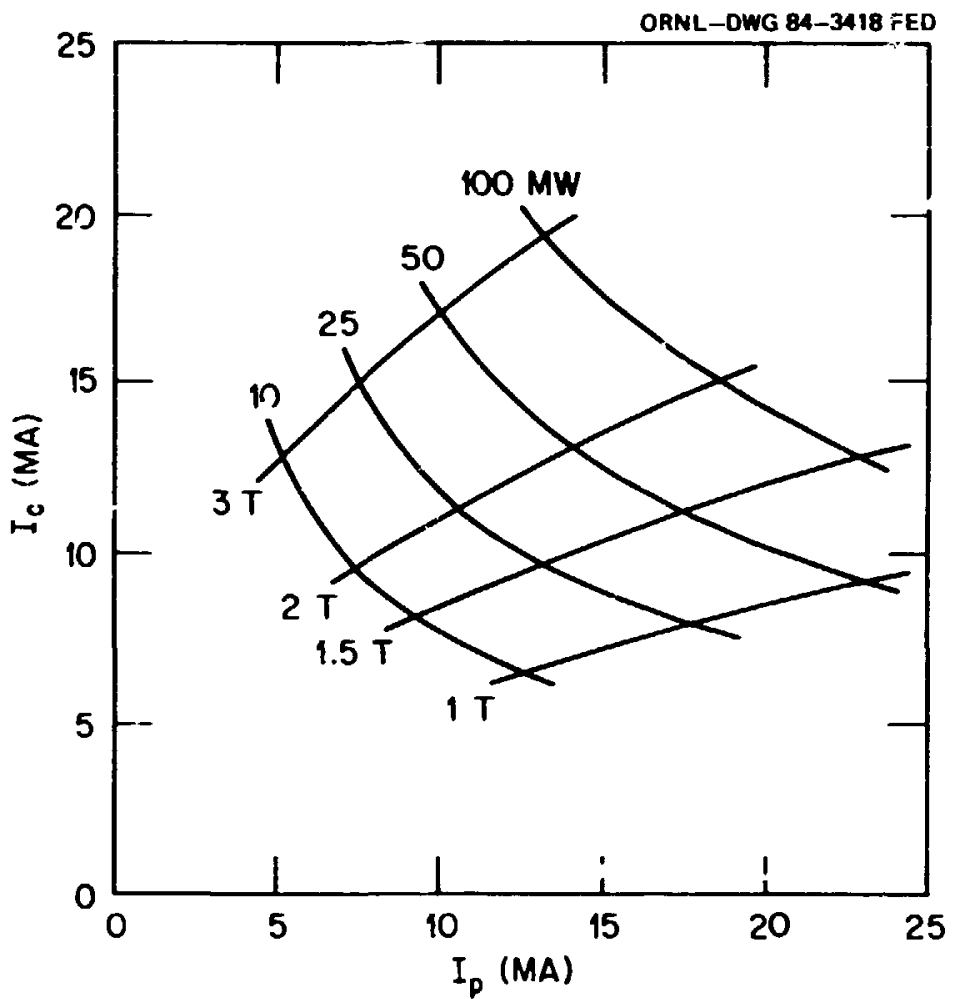

Figure 9 The parameter space of interest in $I_{P}$ and $I_{c}$ for spherical tori having $B$ between 1 and $3 T, P_{D T}$ between 1$)$ and $100 \mathrm{MW}$, and those parameters of Figure 6.

It is of interest to compare a high-field "spherical torus" at $B=12 \mathrm{~T}$ with alternative high-field copper tokamaks at $C_{i g}=1.5$ and $B=12 \mathrm{~T}$ (e.g., a Riggatron-like ${ }^{15}$ ignition device) to obtain an indication of the relative optimism in the spherical torus assumptions as a whole. As Fig. 10 indicates, such a spherical torus with $J_{c}=4.5 \mathrm{kA} / \mathrm{cm}^{2}$ would have $a=0.25 \mathrm{~m}, R=0.9 \mathrm{~m}$, and $I_{P}=6 \mathrm{MA}$. This device is apparently similar to a Riggatron-like device. However, a more challenging TF coil technolcgy is assumed for the Riggatron because of its simultaneous inclusion of an induction solenoid. The relationship between the two compact concepts can be further delinzated rith Fig. 11, which shows that an ignition spherical torus can be well characterized with modest size, magnetic field, and fusion power but with large plasma current and beta. 


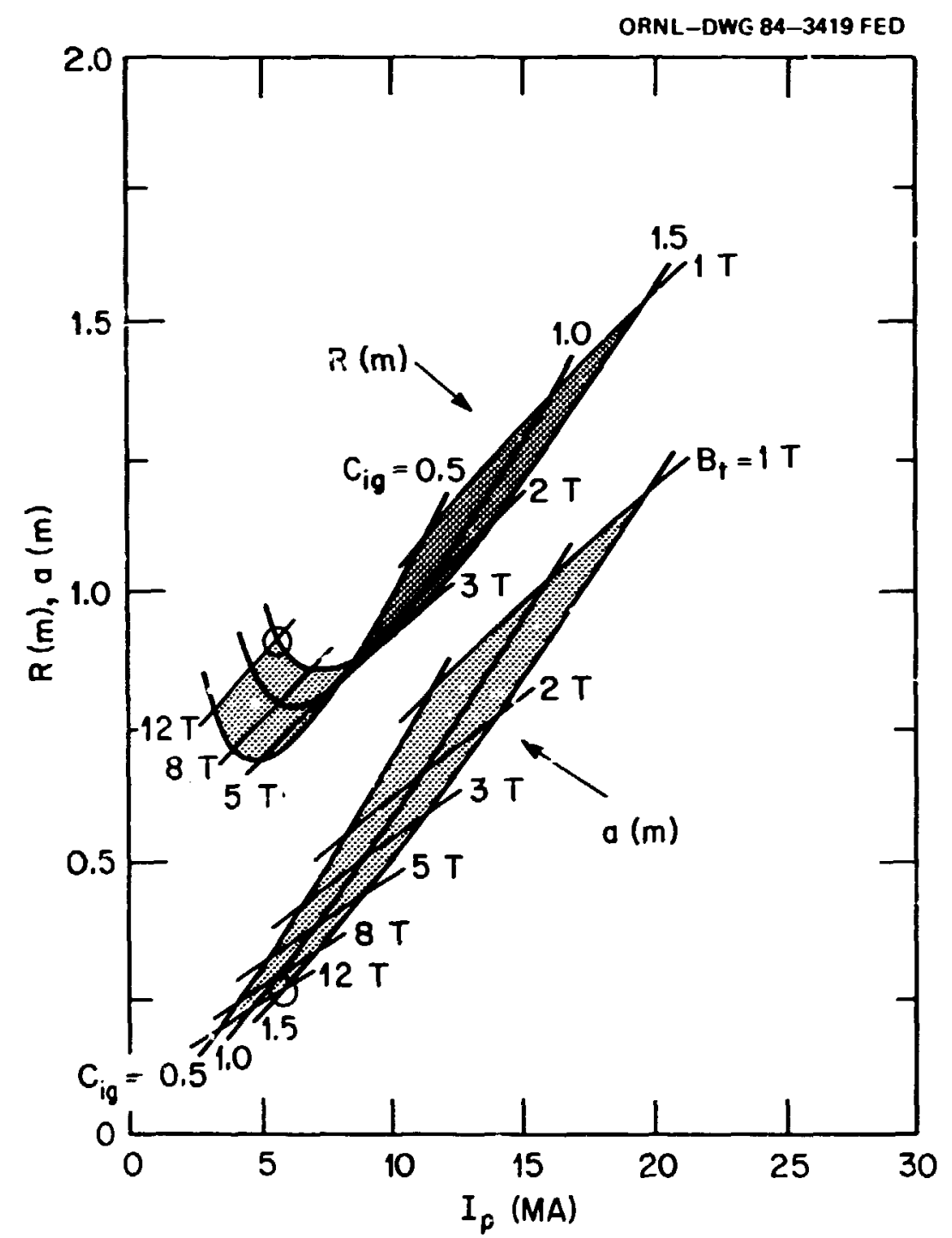

Figure 10 The dependences of $R$ and $a$ on $I_{p}$ ior $B$ ranging from $I$ to $12 \mathrm{~T}$, assuming $q=2.4, \Delta=0.1 a, k$ $=2$, and $J_{c}=4.5 \mathrm{kA} / \mathrm{cm}^{2}$.

\subsection{Typical Examples}

For ignition and burn, typical parameters of a spherical torus are listed in Table 1. Cases for two first wnll concepts are shown. The more conventional approach of a separate firsi wall will lead $t c \mathrm{Q}=1.53 \mathrm{~m}$ and $I_{c}=15.3 \mathrm{MA}$. Eliminating the separate first wall and, 


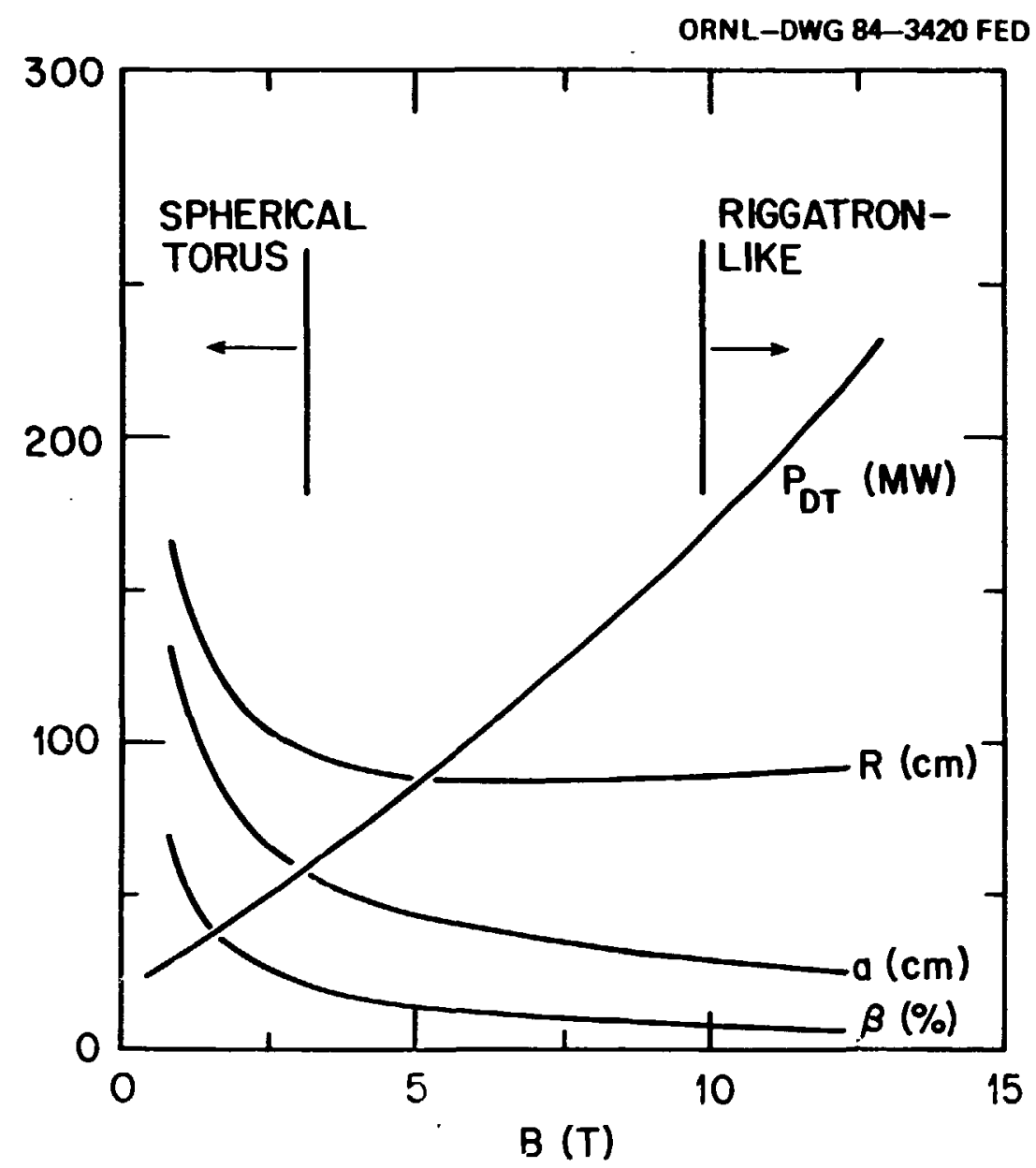

Figure 11 The dependences of $P_{D T}, R, a$, and $\beta$ on $B$ for $C_{k q}=1.5, q=2.4, \Delta=0.1 a, \alpha=2$, and $J_{c}=$ $4.5 \mathrm{kA} / \mathrm{cm}^{2}$, depicting the contrast between spherical tori and Riggatron-like devices.

hence, saving $8 \mathrm{~cm}$ between the plasma and the center conductor post will introduce a reduction of nearly $0.2 \mathrm{~m}$ in $R$ and nearly $2 \mathrm{MA}$ in $I_{a}$ but it will require a more advanced approach to the first wall and vacuum boundary arrangement.

For the high neutron production and wall load useful in technology development, Table 2 illustrates a case with $B=3 \mathrm{~T}$ and $W_{L}=1.0 \mathrm{MW} / \mathrm{m}^{2}$, requiring $R=1.13 \mathrm{~m}$ and $I_{c}=16.9 \mathrm{MA}$. If a modest fusion-power-driven system is desired as a low-cost prototype to a more significant fusion device, a 2 -T system of interest is included in Table 2. 
Table 1. Parameters of sperical terf for toidion

$\operatorname{ming}\left(C_{\text {i }}=1.5\right)$ with $B=2 \mathrm{~T}$,

$J_{c}=3 \mathrm{kA} / \mathrm{cm}^{2}, \alpha=2, T=20 \mathrm{keV}$

\begin{tabular}{lcc}
\hline & & With separate \\
& Advanced & first wall \\
\hline$R(\mathrm{~m})$ & 1.34 & 1.53 \\
$a(\mathrm{~m})$ & 0.88 & 0.97 \\
$R_{c}(\mathrm{~m})$ & 0.38 & 0.40 \\
$I_{c}(\mathrm{MA})$ & 13.4 & 15.3 \\
$I_{P}(\mathrm{MA})$ & 14.0 & 14.1 \\
$P_{D T}(\mathrm{MW})$ & 52 & 60 \\
$W_{L}\left(\mathrm{MW} / \mathrm{m}^{2}\right)$ & 0.62 & 0.54 \\
$P_{R V}(\mathrm{MW})$ & 8.4 & 8.6 \\
$\Delta(\mathrm{m})$ & 0.09 & 0.16 \\
$n\left(! 0^{20} \mathrm{~m}^{-3}\right)$ & 0.66 & 0.59 \\
$\beta$ & 0.26 & 0.24 \\
\hline & & \\
\hline
\end{tabular}

This midget fusion spherical torus has $R=0.8 \mathrm{~m}, a=0.46 \mathrm{~m}, I_{c}=7.9 \mathrm{MA}$, and $I_{P}=$ 5. I MA, requiring $P_{a u x}=2.5 \mathrm{MW}$ based on Mirnov scaling and producing $P_{D T}=$ $4 \mathrm{MW}$ and $W_{L}=0.15 \mathrm{MW} / \mathrm{m}^{2}$.

An example of a sphcrical torus reactor at $B=5 \mathrm{~T}$ is also included in Table 2 . It is scen that a device with $R=2.06 \mathrm{~m}, a=1.2 \mathrm{~m}$, and $I_{p}=34.4 \mathrm{MA}$ would produce fusion power at the $3000-\mathrm{MW}$ level and a neutron wall load at the $17-\mathrm{MW} / \mathrm{m}^{2}$ level. Assuming an H-mode scaling based on twice the confinement time of the Goldston-Kaye scaling, ${ }^{16}$ 
Talk 2. Pannetion of agherieal tori with $\Delta=0.1 \mathrm{a}$

$J_{c}=3 \mathrm{kA} / \mathrm{cm}^{2}, q=24 \mathrm{mat} T=20 \mathrm{kV} \mathrm{for}$

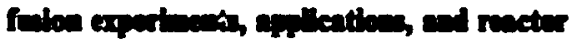

\begin{tabular}{|c|c|c|c|}
\hline & $\begin{array}{l}Q-1 \\
\text { midpet }\end{array}$ & $\begin{array}{l}\text { Neutron production } \\
\text { and wall load }\end{array}$ & Reactor \\
\hline$B(\mathrm{~T})$ & 2 & 3 & 5 \\
\hline$P_{D T}(\mathbf{M W})$ & 4.0 & 53 & 3000 \\
\hline$W_{L}\left(M W / m^{2}\right)$ & 0.15 & 1.0 & 17 \\
\hline$W_{P}(\mathbf{M J})$ & 3.0 & 18.1 & 350 \\
\hline$R(\mathrm{~m})$ & 0.79 & 1.13 & 2.06 \\
\hline$a(m)$ & 0.46 & 0.64 & 1.20 \\
\hline$R_{c}(\mathrm{~m})$ & 0.29 & 0.42 & 0.74 \\
\hline$I_{c}(\mathrm{MA})$ & 7.9 & 16.9 & 51.6 \\
\hline$I_{p}(\mathrm{MA})$ & 5.1 & 10.3 & 34.4 \\
\hline$C_{t g}$ & 0.20 & 1.2 & 22 \\
\hline$n\left(10^{20} \mathrm{~m}^{-3}\right)$ & 0.46 & 1.0 & 2.9 \\
\hline$\beta$ & 0.18 & 0.18 & 0.19 \\
\hline
\end{tabular}

the ignition parameter of this reactor, according to Eq. (13), gives $C_{l g}=1.3$. If Mirnov scaling is used instead, $C_{l g}$ is calculated to be over 20.

\subsection{Configurations}

Feasible configurations for the two examples shown in Table 1 are depicted in Figs. 12 and 13, although these are not necessarily unique to the spherical torus concept. The 


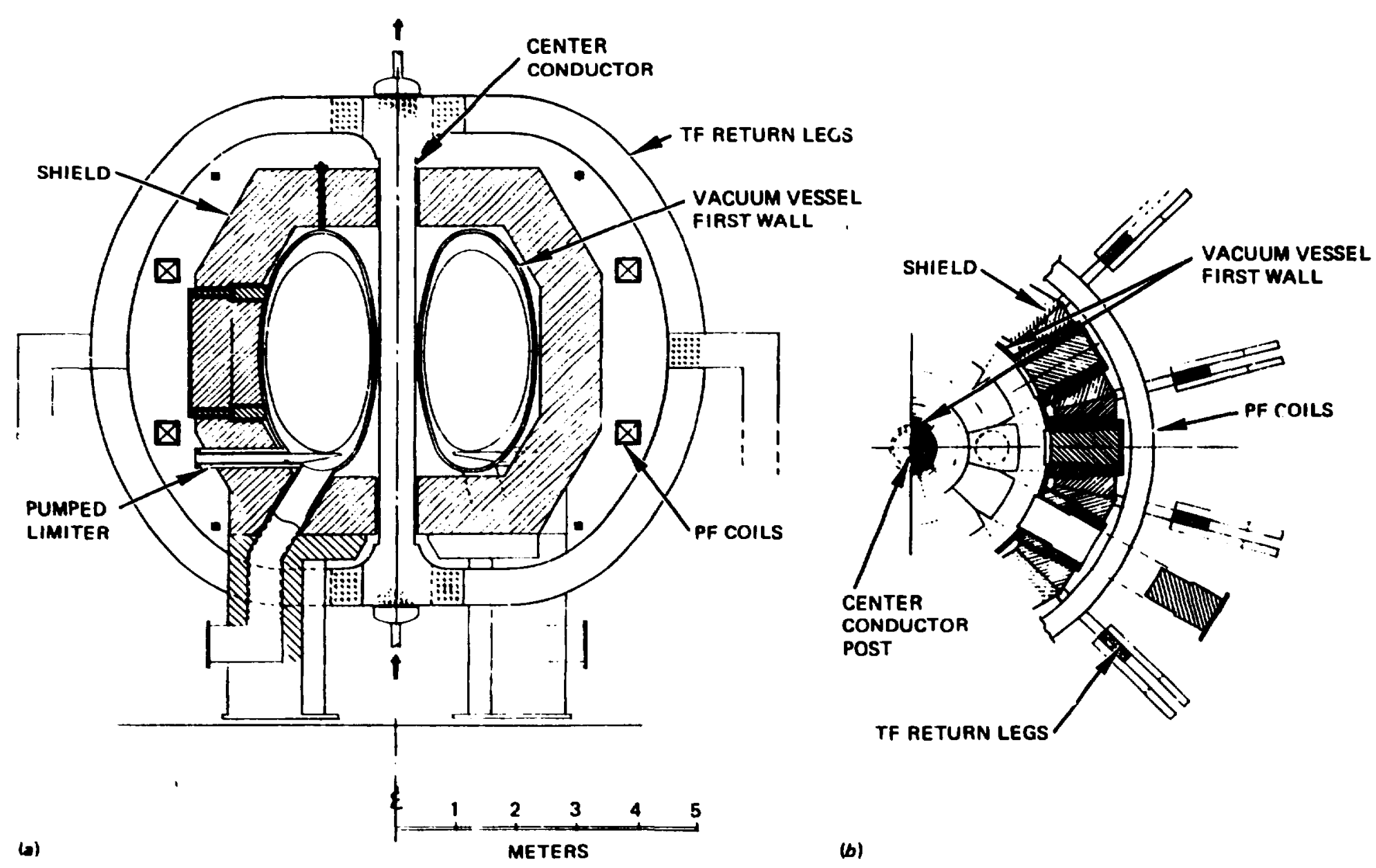

Figure 12 (a) Elevation view and (b) plan view of an ignition spherical torus with soparate fint wall arrangement, internal PF coils, and demountable TF coil retura leges. 

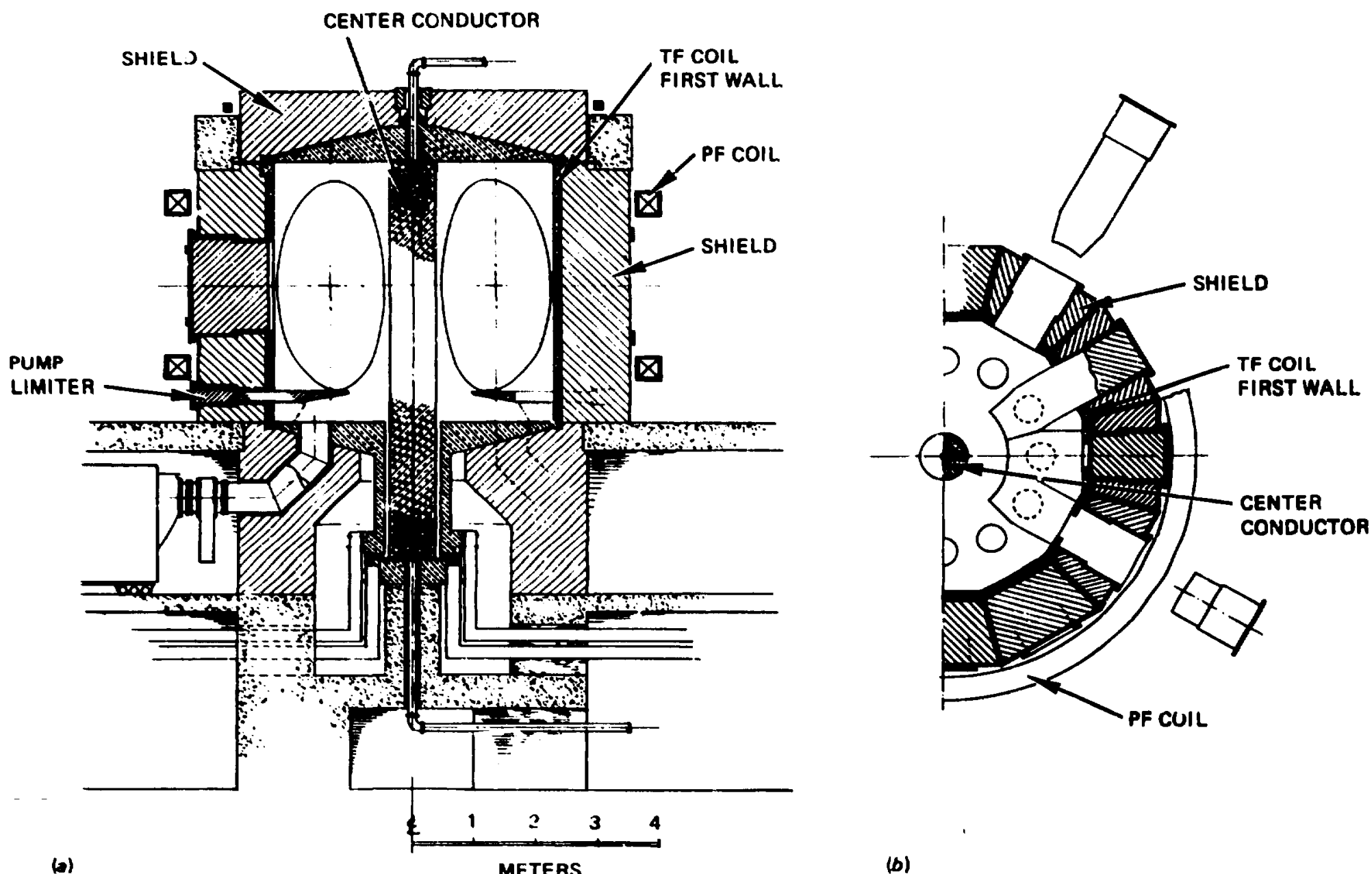

Figure 13 (s) Elevation viow and (b) plan view of an ignition apherical torus with an advanced concoph of combiood firnt wall and tho toraidal field conductor. 
former represents a relatively conventional embodiment that includes a first wall arrangement separate from the center conductor post and the spherical nuclear shield, with demountable TF coil return legs external to the shield and the PF coils. This configuration permits access to the plasma to a degree similar to that in TFCX deaigns.

The latter configuration represents a relatively advanced embodiment that combines the first wall with the ranductor required to carry the return current from the center conductor post. In comparison to the former case, this case permits more flexibility in the arrangement of the shields, is more compact, but permits access to the plasme only in relatively small openings in the first wall-conductor arrangement in order to avoid unacceptable field ripples at the plasma. Several other types of spherical torus embodiments, including a possible combined shield-conductor-first wall arrangement, are also being explored.

In these ignition spherical tori, the center conductor post intercepts less than $5 \%$ of the fusion neutrons.

\section{DISCUSSION}

\subsection{Physics Data Base}

It is important to point out that there is escentially no data base available at the present time for tokamaks with $A$ below 2, although significant $A$-dependences have been revealed through existing tokamak experiments with $A$ ranging from 3 to 5 . The Joint European Torus (JET) and the big D in Doublet III (DIII) have $A$ as low as 2.37 and 2.49 , respectively. These devices will afford further indications of low- $A$ effects in the next few years.

Before an adequate data base for the spherical torus becomes available, shortfalls in plasma confinement, beta, and current drive cannot be ruled out. $A$ confinement shortfall 
would lead primarily to an increase in auxiliary heating power and, bence, to driven systems; a beta shortfall, to reduced fusion power and neutron wall load; and a current drive shortfall, to short burn pulses. However, because of its small unit size, a spherical torus appears to introduce only modest risk compared to a conventional tokamak in generating copious neutrons for use in fusion development.

\subsection{Key Engineering Issues}

The high potential and low cost of D-T spherical tori rely on the successful resolution of a few key engineering issues. These include the fabrication of the center cunductor, the approach of low-voltage, high-current power supplies; and the toroidal field system structure. Various options have been identified:

- For the center conductor, the options rarge from casting to explosive bonding of the single couductor post and to bondirnj: cf ver _mic insulator to multitum plate conductor that could comprise the post.

- For the power supplies, the options range from steady-state homopolar generators to transformer rectifiers for high-duty-cycle operations and to high current lead-based batteries for low-duty-cycle operations.

- For the toroidal field system structire, the options range from demountable external return legs to combined first wall and conductor (and shield-blanket) arrangements.

The examples of Table 1 show the sensitivity of the unit size of an ignition spherical torus to the presence of a separate first wall arrangement in that it substantially increases the plasma major radius and aspect ratio. A similar degree of sensitivity is expected to the variations of the current density over the cross section of the center conductor post. Figure 14 shows that as $J_{c}$ is increased from 3.0 to $6.0 \mathrm{kA} / \mathrm{cm}^{2}, R$ decreases from $>1.3 \mathrm{~m}$ to 


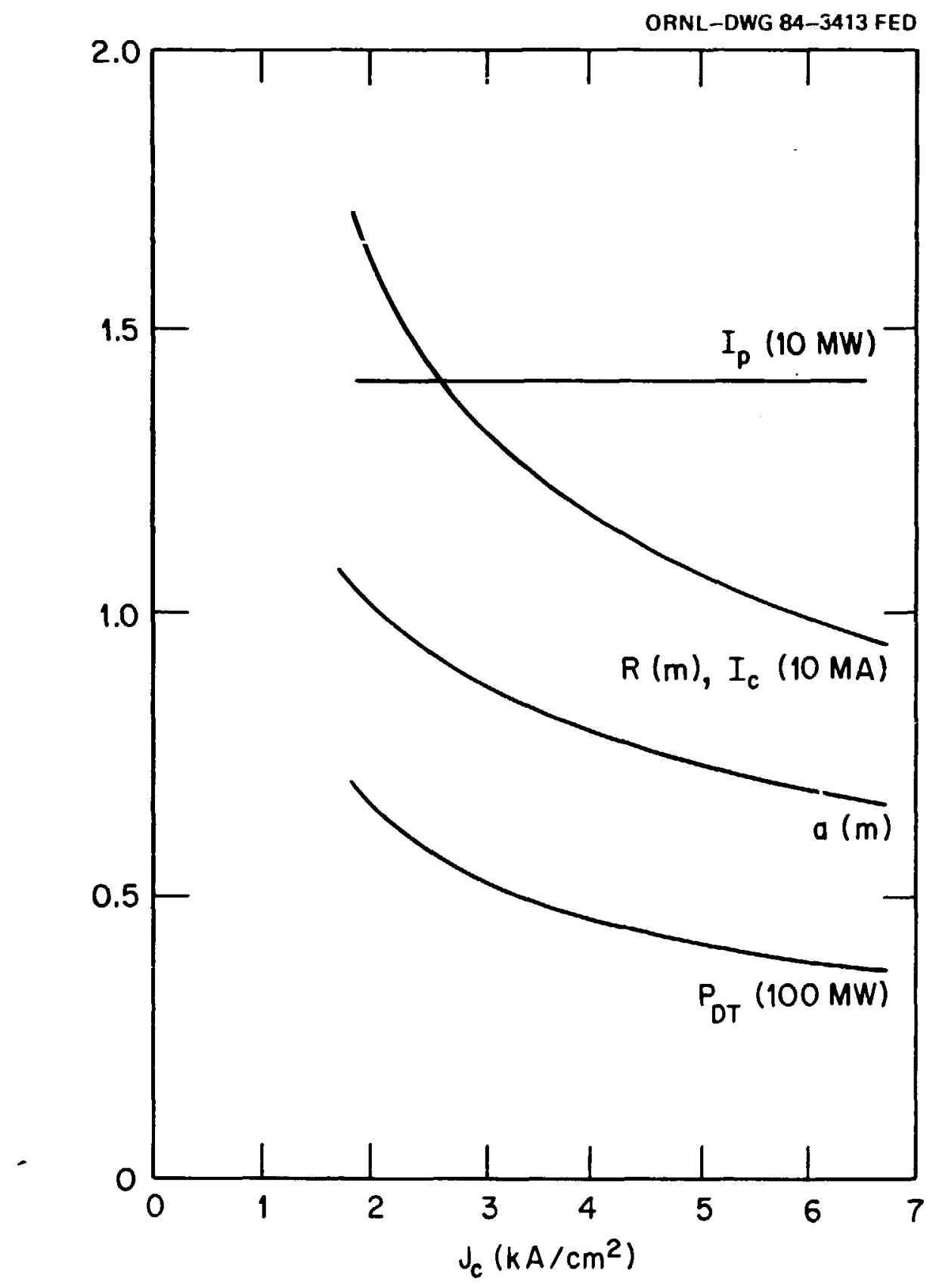

Figure 14 The dependences of $I_{A} R, I_{C} a$, and $P_{D T}$ on $J_{C}$ in spherical tori with $q=2.4, B=2 \mathrm{~T}, \alpha=2$, and $\Delta=0.1 a$. 
$<1.0 \mathrm{~m}$ and $I_{c}$ from $>13 \mathrm{MA}$ to $<10 \mathrm{MA}$. The fusion power also decreases from

- MW to $<40 \mathrm{MW}$. The accompanying reduction in unit size is dramatic in view of the expectation that the unit weight scales between $R^{2}$ and $R^{3}$, suggesting that doubling $J_{c}$ would roughly halve the weight of an ignition spherizal turus device. The technology of high-temperature copper allo; with pressurized water coolant is therefore one of the key issues of a compact, high-performance D-T spherical torus.

\subsection{Comparison With High-Performance TFCX}

Table 3 contains key parameters for an ignition spherical torus and the high-performance copper version of TFCX. Dramatic reductions in the device size, fusion power, and the externally arplied currents in the TF and PF coils are indicated for the spherical torus. These are expected to translate directly to dramatic reductions in the cost of the fusion device (the load module), although significant cost reductions are also expected in its support systems and facilities. A more detailed conceptual design is needed to quantify these potential cost benefits of an ignition spherical torus.

These potential cost reductions are accompanied by changes in risk in the physics and engineering performance of the spherical torus. The pulse length indicated in Table 3 for the spherical turus refers to the time scale of resistive decay of $10 \%$ for the plasma current at an electron temperature of $20 \mathrm{keV}$. Thus, in the absence of inductive current drive or successful noninductive current maintenance schemes, the spherical torus risks having short burn pulse lengths relative to TFCX. In the event that the plasma energy confinement scales much like the plasma volume, such as in the case of neo-Alcator scaling, the spherical torus as presently sized will have an ignition paraneter more than an order of magnitude less than TFCX and will require undesirable levels of auxiliary heating power. 


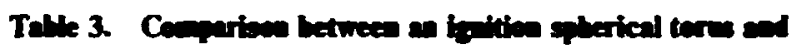

lidperfornence cerper TFCX. Noce that the PF

curreat cited for TPCX bes not inchate the solewid)

\begin{tabular}{lcc}
\hline \multicolumn{1}{c}{ Parameter } & Spherical torus & TFCX \\
\hline Major radius (m) & 1.53 & 2.60 \\
Minor radius (m) & 0.97 & 1.04 \\
Aspect ratio & 1.58 & 2.49 \\
Plasma current (MA) & 14.1 & 10.4 \\
Field on-axis (T) & 2.0 & 4.5 \\
Average toroidal beta (\$) & 24.0 & 6.0 \\
Fusion power (MW) & 60 & 290 \\
Wall load (MW,'m ${ }^{2}$ ) & 0.6 & 1.2 \\
Pulse length (s) & 100 & 300 \\
TF current (MA) & 15.3 & 58.5 \\
PF current (MA) & 10.0 & 39.7 \\
$C_{\text {ig }}$ (Mirnov) & 1.5 & 1.5 \\
$C_{i g}$ (INTOR) & 1.6 & 1.9 \\
$C_{i q}$ (neo-Alcator) & 0.1 & 2.5 \\
\hline
\end{tabular}

These increases in risk are mitigated by some of the intrinsic features of the spherical torus. These include, in the physics area, the high potential for average beta above $20 \%$ and high plasma current, the ease of high plasma elongation, and the substantially reduced plasma inductance relative to TFCX.

In the engineering area, the use of modest magnetic field relieves the need for advanced materials and engineering approaches, although such approaches, when applied 
to critical components of the spherical torus (e.g., the center conductor post), should further its cost-effectivesess. The relatively simple configuration of a spherical torus seems to lend itself to conventional engineering approaches for construction and opens new avenues for design innovation. A D-T spherical torus retains only the center conductor post and, if desired, the ceramic insulator and a separate first wall. In doing so, it also retains the potential of high tolerance to neutron fluence in a compact device relative to more sonventional compact fusion tokamak designs. The modest size and cost of the load module of a spherical tor us make it cost-effective to replace and to improve the load module, given the support systems and facilities. In the case of a $Q=1$ driven D-T spherical torus (Table 2), the cost of the load module is expected to be a relatively small fraction of the support systems and facilities, making it an attractive approach to initiate integrated physics, engineering, and nuclear development of magnetic fusion. These potential risks and benefits can be delineated when a significant data base for a spherical torus becomes available.

Although not discussed here, spherical tori with aspect ratios below 1.3 are also attainable and should be assessed as long as reactor-grade plasmas can be maintained with magnetic fieids less than $1 \mathrm{~T}$. If the plasma scales with $A$ in a fashion similar to that discussed here, then beta values approaching unity and $I_{P}$ values significantly larger than $I_{c}$ become available (Figs. 7 and 11). Similarly, a solenoid inbourd to the plasma can be included to provide partial inductive current drive capability, while aspect ratios below 2 can still be maintained by reducing $B$ and increasing $R$ of the spherical torus (Fig. 15). Coil sets can also be introduced inboard to the plasma to form a bean-shaped plasma cross section while still retaining the spherical torus configuration (Fig. 16). Finally, the spherical torus is expected to have attractive reactor embodiments because of its high beta, compact size, and moderate field. 


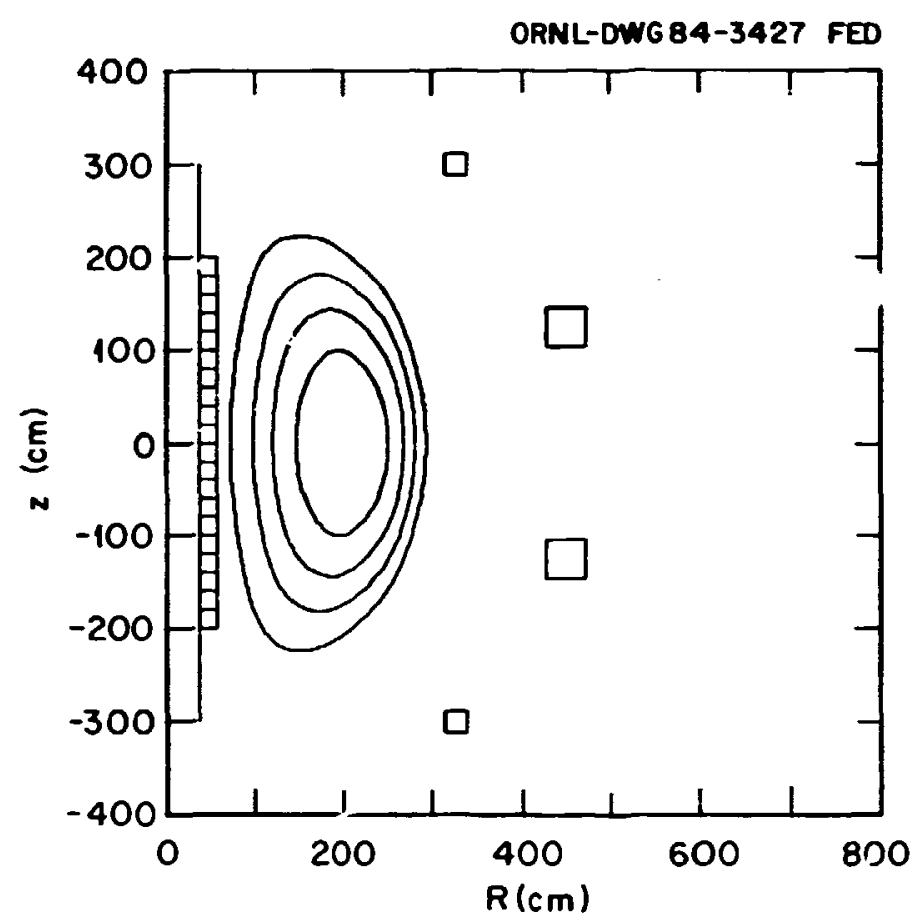

Figure 15 Plasma flux surfaces and PF coil configuration for an ignition spherical torus with an ohmic heating induction solenoid, $R=1.83 \mathrm{~m}, a=1.11 \mathrm{~m}, x=2, B=2 \mathrm{~T}, q=2.8$, and $\beta=21 \%$.

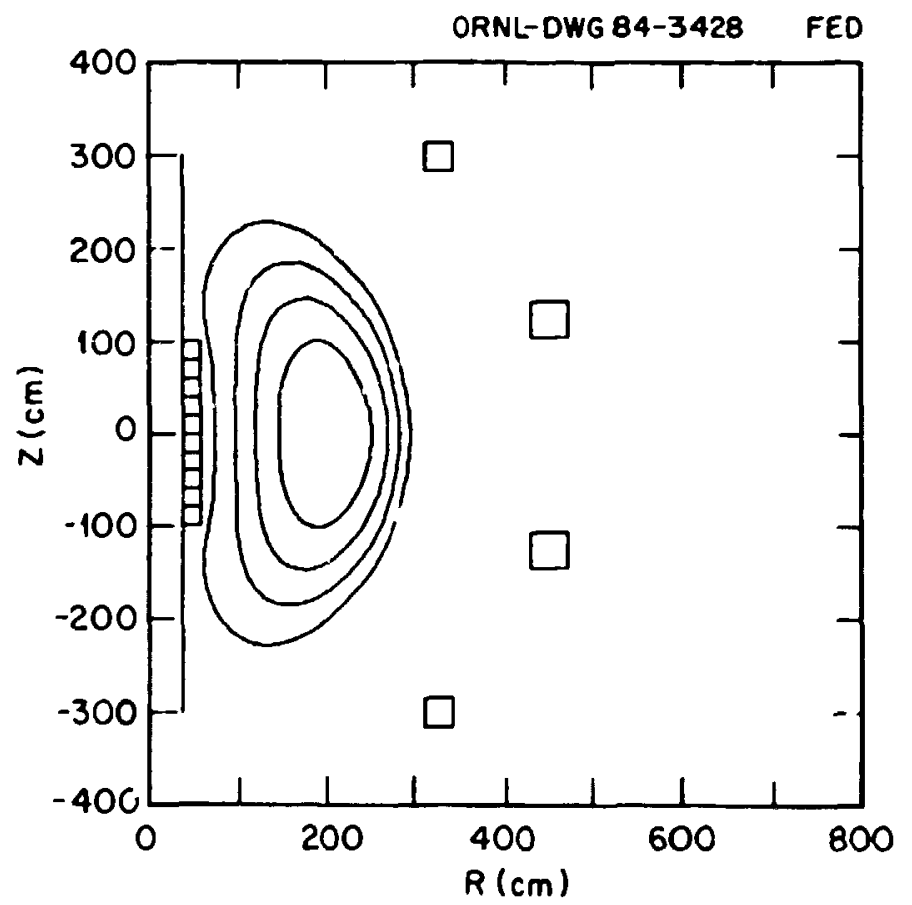

Figure 16 Plama flux surfaces and PF coil configuration for an ignition spherical torus with inboard PF coils to form a bean-shaped plasma, $R=1.77 \mathrm{~m}, a-1.16 \mathrm{~m}, \kappa=2, \beta-2 \mathrm{~T}, q-4.4$, and $\beta=18 \%$. 


\section{Acknowledgments}

It is a pleasure to thank T. E. Shannon for his encouragement of the work. Discussions with him, J. Sheffield, C. A. Flanagan, D. C. Loust/aau, G. R. Dalton, G. E. Gorker, D. J. Strickler, W. R. Hamilton, T. G. Brown, M. H. Kunselman, G. T. Bussell, F. W. Wiffen, S. S. Kalsi, V. D. Lee, S. A. Freije, and D. H. Metzler have substantially contributed to clarifying the potentials and limitations of the spherical torus concept. Special thanks are also due to D. J. Strickler for the MHD equilibrium calculations; to D. C. Lousteau, T. G. Brown, and M. H. Kunselman for the spherical torus configurations used in this paper, and to $\mathbf{R}$. Goldston for discussions on spherical torus reactors.

\section{References}

1. ETF Design Center Team, Engineering Test Facility Mission Statement Document, ORNL,'TM-6733, Oak Ridge National Laboratory (1980).

2. INTOR Group, Nucl. Fusion 23, 1513 (1983).

3. C. A. Flanagan et al. (eds.), Fusion Engineering Device Design Description, ORNL/TM-7948, Oak Ridge National Laboratory (1981).

4. J. A. Schmidt et al., "The Toroidal Fusion Core Experiment (TFCX) Studies," paper IAEA-CN-44/H-I-3, presented at the Tenth International Conference on Plasma Physics and Controlled Nuclear Fusion Research, London, September 12-19, 1984.

5. S. O. Dean, Nucl. Technol./Fusion 4, 302 (1983).

6. L. C. Bernard et al., Nucl. Fusion 23, 1475 (1983). 
7. R. D. Stambough et al., “Tests of Beta Limits as a Function of Plasma Shape in the Doublet III Device," paper IAEA-CN-44/A-IV-2-1, presented at the Tenth Intern:tional Conference on Plasma Physics and Controlled Nuclear Fusion Research, London, September 12-19, 1984.

8. Y-K. M. Peng and R. A. Dory, "Very Small Aspect Ratio Tokamak," ORNL/TM-6535, Oak Ridge National Laboratory (1978).

9. D. J. Strickler et al., "Equilibrium Modeling of the TFCX Polodial Field Coil System," ORNL/FEDC-83/10, Oak Ridge National Laboratory (1984).

10. E. T. Gorbunov, S. V. Mirnov, and V. S. Strelkov, Nucl. Fusion 10, 43 (1970).

11. F. Wagner et al., "Confinement and $\beta_{\mathrm{p}}$-Studies in Neutral-Beam-Heated ASDEX Plasmas," in Plasma Physics and Controlled Nuclear Fusion Research 1982, IAEA, Vienna, 43, 1983.

12. M. Keilhacker et al., "Confinement and $\beta$-Limit Studies in ASDEX H-Mode Discharges," paper IAEA-CN-44/A-II-1, presented at the Tenth International Conference on Plasma Physics and Controlled Nuclear Fusion Research, London, September 12-19, 1984.

13. F. Jobes et al., Phys. Rev. Lett. 52, 1005 (1983); W. Hooke, Comments Plasma Phys. Controlled Fusion 26, 133 (1984); K. Toi, Phys. Rev. Lett. 52, 2144 (1984); R. Motley et al., "Lower Hybrid Current Ramp-Up in the PLT Tokamak," paper IAEA-CN-44/F-II-2, presented at the Tenth International Conference on Plasma Physics and Controlled Nuclear Fusion Research, London, September 12-19, 1984.

14. Y-K. M. Peng et al., Section 4.1 in "FED-A, An Advanced Performance FED Based on Low Safety Factor and Current Drive," ORNL/FEDC-83/1, Oak Ridge National Laboratory (1983). 


\section{$31 / 32$}

15. R. G. Perkins et al., "Compact Tukamak Hybrid Reactor System," paper IAEA-CN44/H-I-4, and B. Coppi et al., "Physics of Plasmas close to the Lawson Limit and Under Burn Conditions," paper IAEA-CN-44/E-II-4, presented at the Tenth International Conference on Plasma Physics and Controlled Nuclear Fusion Research, London, September 12-19, 1984.

16. R. Goldston, Comments Plasma Phys. Controlled Fusion 26, 87 (1984). 
ORNL/FEDC-84/7

Dist. Category UC-20 c,d

INTERNAL DISTRIBUTION

\author{
1. S. E. Attenberger \\ 2. D. B. Batchelor \\ 3. D. D. Bates \\ 4. D. R. Baumgardner \\ 5. L. A. Berry \\ 6. B. A. Carreras \\ 7. R. J. Colchin \\ 8. E. C. Crume \\ 9. R. A. Dory \\ 10. J. L. Dunlap \\ 11. G. E. Gorker \\ 12. J. R. Haines \\ 13. H. H. Haselton \\ 14. G. R. Haste \\ 15. C. L. Hedrick \\ 16. D. L. Hillis \\ 17. T. C. Jernigan \\ 18. S. S. Kalsi \\ 19. P. W. King \\ 20. E. A. Lazarus \\ 21. J. T. Mihalczo \\ 22. G. H. Neilson \\ 23. R. L. Reid
}

24. J. A. Rome

25. M. J. Saltmarsh

26. J. Sheffield

27. D. A. Spong

28. V. C. Srivastava

29. D. W. Swain

30. N. A. Uckan

31. T. Uckan

32. T. L. White

33. K. F. Wu

34. J. B. Wilgen

35. R. Zuhr

36. S. K. Borowski

37-41. Y-K. M. Peng

42-43. Laboratory Records Department

44. Laboratory Records, ORNL-RC

45. Document Reference Section

46. Central Research Library

47. ORNL Patent Office

48. Fusion Energy Division Library

49. Fusion Energy Division Publications Office

\section{EXTERNAL DISTRIBUTION}

50. M. A. Abdou, School of Engineering and Applied Science, 6288 Boelter Hall, University of California, Los Angeles, CA 90024

51. C. A. Anderson, Westinghouse Electric Corporation, Advanced Energy Systems Division, P.O. Box 158, Madison, PA 15663

52. J. L. Anderson, CMB-3, Mail Stop 348, Los Alamos National Laboratory, P.O. Box 1663, Los Alamos, NM 87545

53. C. C. Baker, FPP/208, Argonne National Laboratory, 9700 South Cass Avenue, Argonne, IL 60439

54. D. S. Beard, Office of Fusion Energy, Office of Energy Research, Mail Stop G-256, U.S. Department of Energy, Washington, DC 20545

55. K. L. Black, Department E452, McDonnell Douglas Astronautics Company, P.O. Box 516, St. Louis, MO 63166

56. R. Botwin, C47-05, Grumman Aerospace Corporation, P.O. Box 31, Bethpage, NY 11714 
57. W. B. Briggs, McDonnell Douglas Astronautics Company, P.O. Box 516, St. Louis, MO 63166

58. J. N. Brooks, FPP/207, Argonne National Laboratory, 9700 South Cass Avenue, Argonne, IL 60439

59. S. C. Burnett, GA Technologies, Inc., P.O. Box 81608, San Diego, CA 92138

60. J. D. Callen, Department of Nuclear Engineering, University of Wisconsin, Madison, WI 53706

61. D. R. Cohn, MIT Plasma Fusion Center, 167 Albany Street, Cambridge, MA 02139

62. J. W. Coursen, C36-05, Grumman Aerospace Corporation, P.O. Box 31, Bethpage, NY 11714

63. R. W. Conn, School of Chemical, Nuclear, and Thermal Engineering, Boelter Hall, University of California, Los Angeles, CA 90024

64. J. G. Crocker, EG\&G Idaho, P.O. Box 1625, Idaho Falls, ID 83401

65. G. R. Dalton, Department of Nuclear Engineering Science, Nuclear Science Center, University of Florida, Gainesville, FL 32611

66. R. C. Davidson, Massachusetts Institute of Technology, 77 Massachusetts Avenue, Cambridge, MA 02139

67. N. A. Davies, Office of Fusion Energy, Office of Energy Research, Mail Station G-256, U.S. Department of Energy, Washington, DC 20545

68. S. O. Dean, Director, Fusion Energy Development, Science Applications, Inc., 2 Professional Drive, Suite 249, Gaithersburg, MD 20760

69. J. F. Decker, Office of Fusion Energy, Office of Energy Research, Mail Stop G-256, U.S. Department of Energy, Washington, DC 20545

70. D. DeFreece, E451, Building 81/1/B7, McDonnell Douglas Astronautics Company, P.O. Box 516, St. Louis, MO 63166

71. J. N. Doggett, L-441, Lawrence Livermore National Laboratory, P.O. Box 808, Livermore, CA 94550

72. H. Dreicer, Division Leader, CRT, Los Alamos National Laboratory, P.O. Box 1663, Los Alamos, NM 87545

73. D. Ehst, Argonne National Laboratory, 9700 South Cass Avenue, Argonne, IL 60439

74. G. A. Eliseev, I. V. Kurchatov Institute of Atomic Energy, P.O. Box 3402, 123182 Moscow, U.S.S.R.

75. F. Farfaletti-Casali, Engineering Division, Joint Research Center, Ispra Establishment, 21020 Ispra (Varese), Italy

76. P. A. Finn, Fusion Power Program, Argonne National Laboratory, 9700 South Cass Avenue, Argonne, IL 60439

77. H. K. Forsen, Bechtel Group, Inc., Research \& Engineering, P.O. Box 3965, San Francisco, CA 94119

78. J. S. Foster, Jr., Building R4-2004, TRW Defense and Space Systems, 1 Space Park, Redondo Beach, CA 90278

79. T. K. Fowler, Associate Director for MFE, L-436, Lawrence Livermore National Laboratory, P.O. Box 808, Livermore; CA 94550

80. J. W. French, EBASCO Services, Inc., Forrestal Campus, CN-59, Princeton University, Princeton, NJ 08544

81. H. P. Furth, Director, Princeton Plasma Physics Laboratory, P.O. Box 451, Princeton, NJ 08544

82. J. G. Gavin, Jr., President, A01-11, Grumman Aerospace Corporation, P.O. Box 31, Bethpage, NY 11714 
83. G. Gibson, Westinghouse Electric Corporation, Advanced Energy Systems Division, P.O. Box 158, Madison, PA 15663

84. J. R. Gilleland, Manager, Fusion Project, GA Technologies, Inc., P.O. Box 81608, San Diego, CA 92138

85. V. A. Glukhikh, Scientific-Research Institute of Electro-Physical Apparatus, 188631 Leningrad, U.S.S.R.

86. M. Y. Gohar, Argonne National Laboratory, 9700 South Cass Avenue, Argonne, IL 60439

87. R. W. Gould, Department of Applied Physics, California Institute of Technology, Pasadena, CA 91109

88. M. W. Griffin, Department E236, McDonnell Douglas Astronautics Company, P.O. Box 516, St. Louis, MO 63166

89. C. R. Head, Office of Fusion Energy, Office of Energy Research, Mail Stop G-256, U.S. Department of Energy, Washington, DC 20545

90. C. D. Henning, Lawrence Livermore National Laboratory, P.O. Box 808, Livermore, CA 94550

91. J. J. Holmes, Westinghouse-Hanford Engineering Development Laboratory, P.O. Box 1970, Richland, WA 99352

92. D. Hwang, Princeton Plasma Physics Laboratory, P.O. Box 451, Princeton, NJ 08544

93. J. B. Joyce, Princeton Plasma Physics Laboratory, P.O. Box 451, Princeton, NJ 08544

94. R. A. Krakowsi, CTR-12, Mail Stop 641, Los Alamos National Laboratory, P.O. Box 1663, Los Alamos, NM 87545

95. G. L. Kulcinski, University of Wisconsin, Department of Nuclear Engineering, Engineering Research Building, Room 439, 1500 Johnson Drive, Madison, WI 53706

96. D. L. Kummer, McDonnell Douglas Astronautics Company, P.O. Box 516, St. Louis, MO 63166

97. D. G. McAlees, Exxon Nuclear Company, Inc., 2101 Horn Rapids Road, Richland, WA 99352

98. W. Marton, Office of Fusion Energy, Office of Energy Research, Mail Station G-256, U.S. Department of Energy, Washington, DC 20545

99. L. G. Masson, EG\&G Idaho, Idaho National Engineering Laboratory, P.O. Box 1625, Idaho Falls, ID 83401

100. D. M. Meade, Princeton Plasma Physics Laboratory, P.O. Box 451, Princeton, NJ 08544

101. A. T. Mense, Building 107, Post B2, McDonnell Douglas Astronautics Company, P.O. Box 516, St. Louis, MO 63166

102. R. W. Moir, Lawrence Livermore National Laboratory, P.O. Box 808, Livermore, CA 94550

103. D. B. Montgomery, MIT Plasma Fusion Center, 167 Albany Street, Cambridge, MA 02139

104. A. E. Munier, Grumman Aerospace Company, P.O. Box 31, Bethpage, NY 11714

105. R. E. Nygren, FPP/207, Argonne National Laboratory, 9700 South Cass Avenue, Argonne, IL 60439

106. T. Ohkawa, GA Technologies, Inc., P.O. Box 81608, San Diego, CA 9213i

107. J. A. O'Toole, Plasma Physics Laboratory, Building I-P, Room 8A, James Forrestal Campus, P.O. Box 451, Princeton, NJ 08544 
108. R. R. Parker, Francis Bitter National siaznet Laboratory, 170 Albany Street, Cambridge, MA 02139

109. B. Pease, Culham Laboratory, Abingt'on, Oxfordshire OX14 3DB, United Kingdom

110. M. Pelovitz, Princeton Plasma Physics i aboratory, P.O. Box 451, Princeton, NJ 08544

111. F. W. Perkins, Princeton Plasma Physics Laboratory, P.O. Box 451, Princeton, NJ 08544

112. M. Porkolab, Massachusetts Institute of Technology, 77 Massachusetts Avenue, Cambridge, MA 02139

113. D. E. Post, Princeton Plasma Physics Laboratory, P.O. Box 451, Princeton, NJ 08544

114. L. K. Price, Department of Energy, Oak Ridge Operations, P.O. Box E, Oak Ridge, TN 37831

115. R. E. Price, Office of Fusion Energy, Office of Energy Research, Mail Station G-256, U.S. Lepartment of Energy, Washington, DC 20545

116. F. A. Puhn, GA Technologies, Inc., P.O. Box 81608, San Diego, CA 92138

117. J. Purcell, GA Technologies, Inc., P.O. Box 81608, San Diego, CA 92138

118. R. V. Pyle, University of California, Lawrence Berkeley Laboratory, Berkeley, CA 94720

119. J. M. Rawls, GA Technologies, Inc., P.O. Box 81608, San Diego, CA 92138

120. M. Roberts, Office of Fusion Energy, Office of Energy Research, Mail Stop G-256, U.S. Department of Energy, Washington, DC 20545

121. J. D. Rogers, Los Alamos National Laboratory, P.O. Box 1663, Los Alamos, NM 87545

122. M. L. Rogers, Monsanto Research Corporation, Mound Laboratory Facility, P.O. Box 32, Miamisburg, OH 45342

123. M. N. Rosenbluth, RLM 11.218, Institute for Fusion Studies, University of Texas, Austin, TX 78712

124. P. H. Rutherford, Princeton Plasma Physics Laboratory, P.O. Box 451, Princeton, NJ 08544

125. P. H. Rutherford, Princeton Plasma Physics Laboratory, P.O. Box 451, Princeton, NJ 08544

126. D. D. Ryutov, Institute of Nuclear Physics, Siberian Branch of the Academy of Sciences of the U.S.S.R., Sovetskaya St. 5, 630090 Novosibirsk, U.S.S.R.

127. J. A. Schmidt, Princeton Plasma Physics Lahoratory, P.O. Box 451, Princeton, NJ 08544

128. J. Schultz, MIT Plasma Fusion Center, 167 Albany Street, Cambridge, MA 02139

129. F. R. Scott, Electric Power Research Institute, P.O. Box 10412, Palo Alto, CA 94304

130. G. Sheffield, Princeton Plasma Physics Laboratory, P.O. Box 451, Princeton, NJ 08544

131. I. Shpigel, Lebedev Physical Institute, Leninsky Prospect 53, 117924 Moscow, U.S.S.R.

132. D. Smith, Materials Science Division, Argonne National Laboratory, 9700 South Cass Avenue, Argonne, IL 60439

133. L. Southworth, GA Technologies, Inc., P.O. Box 81608, San Diego, CA 92138

134. W. M. Stacey, Jr., Georgia Institute of Technology, School of Nuclear Engineering, Atlanta, GA 30332 
135. D. Steiner, Rensselaer Polytechnic Institute, Troy, NY 12181

136. E. Stern, Grumanan Aerospace Corporation, CN-59, Forrestal Campus, Princeton, NJ 08544

137. P. M. Stone, Office of Fusion Energy, Office of Energy Rssearch, Mail Station G-256, U.S. Department of Energy, Washington, DC 20545

138. I. N. Sviatoslavsky, Room 33, Engineering Research Building, 1500 Johnson Drive, University of Wisconsin, Madison, WI 53706

139. R. E. Tatro, Manager, Energy Systems, M.Z. 16-1070, General Dynamies-Convair Division, P.O. Box 80847, San Diego, CA 92138

140. F. Thomas, B-20-5, Grumman Aerospace Corporation, Bethpage, NY 11714

141. K. I. Thomassen, Lawreace Livermore National Laboratory, P.O. Box 808, Livermore, CA 94550

142. R. J. Thome, Fras.cis Bitter National Magnet Laboratory, 170 Albany Street, Cambridge, MA 02139

143. V. T. Tolok, Kharkov Physical-Technical Institute, Academical St. 1, 310108 Kharkov, U.S.S.R.

144. C. Trachsel, McDonnell Douglas Astronautics Company, P.O. Box 516, St. Louis, MO 63166

145. A. W. Trivelpiece, Office of Fusion Energy, Office of Energy Research, Mail Station G-256, U.S. Department of Energy, Washington, DC 20545

146. L. R. Turner, Fusion Power Program, Argonne National Laboratory, 9700 South Cass Avenue, Argonne, IL 60439

147. E. H. Valeo, Princeton Plasma Physics Laboratory, P.O. Box 451, Princeton, NJ 08544

148. R. Varma, Physical Research Laboratory, Navrangpura, Ahmedabad, India

149. K. E. Wakefield, Princeton Plasma Physics Laboratory, P.O. Box 451, Princeton, NJ 08544

150. J. C. Wesley, GA Technologies, Inc., P.O. Box 81608, San Diego, CA 92138

151. H. Willenberg, Mathematical Sciences Northwest, Inc., P.O. Box 1887, Bellevue, WA 98009

152. J. E. C. Williams, Francis Bitter National Magnet Laboratory, 170 Albany Street, Cambridge, MA 02139

153. H. H. Yoshikawa, W/A-62, Hanford Engineering Development Laboratory, P.O. Box 1970, Richland, WA 99352

154. K. M. Young, Princeton Plasma Physics Laboratory, P.O. Box 451, Princeton, NJ 08544

155. N. E. Young, EBASCO Services, Inc., Princeton Plasma Physics Laboratory, P.O. Box 451, Princeton, NJ 08544

156. Bibliothek, Max-Planck-Institut fur Plasmaphysik, D-8046 Garching bei Munchen, Federal Republic of Germany

157. Bibliothek, Institut fur Plasmaphysik, KFA, Postfach 1913, D-5170 Julich, Federal Republic of Germany

158. Bibliotheque, Service du Confinement des Plasmas, CEA, B.P. No. 6, 92 Fontenayaux-Roses (Seine), France

159. Documentation S.I.G.N., Department de la Physique du Plasma et de la Fusion Controlee, Association EURATOM-LEA, Centre d'Etujes Nucleaires, B.P. 85, Centre du Tri, 38041 Grenoble, France

160. Library, Centre de Recherches er. Physique des Plasmas, 21 Avenue des Bains, 1007 Lausanne, Switzerland 
161. Library, Culham Laboratory, UKAEA, Abingdon, Oxfordshire, OX14 3DB, England

162. Library, FOM Instituut voor Plasma-Fysica, Rijnhuizen, Jutphaas, Netherlands

163. Library, Institute of Physics, Academia Sinica, Beijing, Pcoples Republic of China

164. Library, Institute for Plasma Physics, Nagoya University, Nagoya 464, Japan

165. Library, International Centre for Theoretical Physics, Trieste, Italy

166. Library, JET Joint Undertaking, Abingdon, Oxfordshire, OX14 3DB, England

167. Library, Laboratorio Gas Ionizzati, Frascati, Italy

168. Plasma Research Laboratory, Australian National Laboratory, P.O. Box 4, Canberra, ACT 2000, Australia

169. Thermonuclear Library, Japan Atomic Energy Research Institute, Tokai, Naka, Ibaraki, Japan

170. Library, Plasma Physics Laboratory, Kyoto University, Gokasho, Uji, Kyoto, Japan

171. Office of the Assistant Manager for Energy Research and Development, Department of Energy, Oak Ridge Operations, Oak Ridge, TN 37830

172-366. Give. distribution as shown in TID-4500, Magnetic Fusion Energy (Category Distribution UC-20 c,d: Reactor Materials and Fusion Systems) 